\title{
Sovereign default and imperfect tax enforcement
}

\author{
Francesco Pappada \\ Yanos Zylberberg
}

Discussion Paper 19 / 714

29 May 2019

器

Department of Economics

University of Bristol

Priory Road Complex

Bristol BS8 1TU

United Kingdom 


\title{
Sovereign default and imperfect tax enforcement*
}

\author{
Francesco Pappadà $\quad$ Yanos Zylberberg
}

May 29, 2019

\begin{abstract}
We show that, in many countries, tax compliance is volatile and markedly responds to fiscal policy. To explore the consequence of this novel stylized fact, we build a model of sovereign debt with limited commitment and imperfect tax enforcement. Fiscal policy persistently affects the size of the informal economy, which impact future fiscal revenues and thus default risk. This mechanism captures one key empirical regularity of economies with imperfect tax enforcement: the low sensitivity of debt price to fiscal consolidations. The interaction of imperfect tax enforcement and limited commitment strongly constrains the dynamics of optimal fiscal policy. During default crises, high tax distortions force the government towards extreme fiscal policies, notably including costly austerity spells.
\end{abstract}

JEL: E02, E32, E62, F41, H20.

\footnotetext{
*Pappadà: Banque de France, International Macroeconomics Division, email: francesco.pappada@banque-france.fr. Zylberberg: University of Bristol, CESifo, email: yanos.zylberberg@bristol.ac.uk. This paper previously circulated under the title "Hanging off a cliff: fiscal consolidations and default risk". We thank seminar participants at the Banque de France, Berkeley, CREST, EUI, Graduate Institute Geneva, HEC Lausanne, IMF, Northwestern, PSE, Università di Siena, University of Bristol, University of Virginia, the "8th Joint French Macro Workshop" (2017), the EEA-ESEM (2016), the Midwest Macro Meetings (2017), the Salento Macro Meetings (2017), the ADEMU conference (TSE, 2018), the BGSE Summer Forum (2018) and the SED (2018) for useful comments. The views expressed in this paper are those of the authors and do not necessarily represent those of the Banque de France or of the Eurosystem. The usual disclaimer applies.
} 


\section{Introduction}

The European sovereign debt crisis of 2009-2014 has seen large fiscal consolidations being implemented in peripheral European economies plagued by tax evasion. Despite their unprecedented magnitude, these fiscal consolidations did not reduce debt service and exacerbated the economic downturn. Economies may experience long periods of high taxes, depressed demand and high default risk - a phenomenon commonly referred to as austerity trap in the media.

In this paper, we study the dynamics of fiscal policy and default risk when tax enforcement is imperfect. First, we document novel stylized facts about the dynamics of tax evasion, most notably its volatility and sensitivity to tax rates. Second, we provide a model of sovereign debt with limited commitment in order to explore how fluctuations in tax compliance affect the dynamics of fiscal policy and default risk.

We construct a new measure of tax compliance based on Value-Added-Taxes (VAT), and we uncover the following key stylized facts. ${ }^{1}$ Tax compliance is volatile, and there is a large heterogeneity in such volatility across countries. The volatility of tax compliance is driven by its pro-cyclicality and its sensitivity to tax rates. In some economies with imperfect tax enforcement, a larger share of taxpayers hide their activity in downturns and in periods of austerity. In contrast with the standard behavioral response, the magnitude of fluctuations in tax compliance implies sharply decreasing returns to taxes, and some economies display an extreme form of fiscal fatigue (Ghosh et al., 2013).

We explore the implications of fluctuations in tax compliance on the dynamics of optimal fiscal policy in a model where a benevolent government uses fiscal policy as a consumption-smoothing instrument. The key ingredients of the model are (i) imperfect tax enforcement and (ii) limited commitment. The government stabilizes consumption on behalf of the household, but does so through a distortionary tax. Entrepreneurs can adopt two technologies in order to produce the final good: an unobserved technology — which constitutes the informal sector of the economy - and a verifiable technology - the formal sector - in which there are production complementarities. ${ }^{2}$ We assume that this choice is staggered, in a similar manner as Calvo

\footnotetext{
${ }^{1}$ We use the measure of VAT compliance as a proxy for general tax compliance, and there may be differential responses to different tax instruments that we ignore. The rationale for analyzing VAT is manyfold: it constitutes a large share of tax revenues, even more so in developing economies; it is an important adjustment tool at business cycle frequency; reconstructing counterfactual tax revenues under perfect tax compliance requires very few assumptions.

${ }^{2}$ In practice, the level of tax compliance is the outcome of evasion by taxpayers and the degree of tax enforcement by the government. We focus on fluctuations in tax compliance that stem from the choice of taxpayers to declare their activity. We therefore consider the effort by the government in uncovering undeclared activity as constant, both with respect to the cycle and to changes in
} 
(1983), and each entrepreneur may be able to reset technology with a certain probability in each period. An increase in tax rate distorts the technological choice of entrepreneurs, diverts investment away from the formal sector, and further affects the returns in the formal sector through production complementarities. This response decreases both the contemporary and future cost of raising tax revenues. The government has limited commitment such that debt prices reflect future incentives to default, and thus the degree to which the economy is expected to be distorted. Finally, there are two sources of punishment which give (limited) commitment to the government following a default: market exclusion and a direct output cost possibly reflecting a failure of the domestic banking sector (Mendoza and Yue, 2012).

The novelty of the model is to introduce dynamic distortions through tax evasion. In standard models of sovereign debt with limited commitment (e.g., Eaton and Gersovitz, 1981; Arellano, 2008), default risk depends on the debt level and an exogenous state variable, e.g., current productivity. In such benchmark, a fiscal consolidation reduces future debt levels and unambiguously lowers default risk. By contrast, our model adds another endogenous state variable which affects default risk: the expected distortions as captured by current technological choices. A fiscal consolidation affects the contemporary choice of entrepreneurs, which increases the future expected cost of raising tax revenues and tilts the future trade-off between repayment and default. This indirect effect mitigates the gains in debt service through the standard "fiscal surplus" effect: fiscal consolidations may not unambiguously lower default risk. ${ }^{3}$

The model displays interesting dynamics during default risk episodes. An economy facing low distortions can both stabilize debt levels and domestic consumption through fiscal policy. In these environments, default risk episodes lead to mild fiscal consolidations with reasonably low default risk. In stark contrast, an economy with high distortions is pushed towards extreme fiscal policies under the same circumstances. One such extreme is the equivalent of an austerity trap: Investors have low expectations on potential reimbursement thereby preventing the government from accumulating further deficits, and the (debt) price effect of fiscal consolidations is very low. The economy either escapes the austerity trap after a negative shock and

tax rates. This is consistent with the idea that changes in tax enforcement result from structural reforms implemented at a lower frequency.

${ }^{3}$ Letting $q(b, \gamma)$ denote the debt price as a function of contracted debt $b$ and the size of the formal sector $\gamma$, we have that:

$$
\frac{d q}{d \tau}=\frac{\partial q}{\partial b} \frac{d b}{d \tau}+\frac{\partial q}{\partial \gamma} \frac{d \gamma}{d \tau}
$$

and any increase in tax rate $\tau$ would affect default risk through a fiscal surplus effect (i.e., the decrease in debt $b$ ) and a tax evasion effect (i.e., the decrease in the size of the formal sector $\gamma$ ). 
the government defaults. Or the economy needs a large push to re-create some fiscal space and weaken the impact of the "tax compliance" behavioral response.

We calibrate and simulate our model with aggregate productivity shocks and public expenditure shocks. We use three moments uncovered in the empirical section to calibrate important unobserved fundamentals characterizing the choice of entrepreneurs. The level of tax compliance and its elasticity of tax rates mostly pin down two quantities which affect the contemporaneous trade-off faced by entrepreneurs, i.e., the distribution of returns in the informal sector and the level of complementarities in the formal sector. ${ }^{4}$ The persistence of tax compliance is mostly driven by the staggered technological choice, and the empirical persistence of tax compliance pins down the period probability to reset technology. The remaining parameters of the model are calibrated following standard models of sovereign defaults (Aguiar and Gopinath, 2006; Arellano, 2008). We assess the model performance through its ability to reproduce - across different economic environmentsthe sensitivity of debt prices to fiscal policy. Without being a targeted moment, the correlation between fiscal surplus and default risk is small in the highly-distorted economy, as in the data: the negative impact of future distortions (through current technological choices) alleviates the gains from the reduction in debt levels.

The model rationalizes the rise of two (opposite and) extreme fiscal policies during default crises. Most often, the government enters costly periods of austerity. These austerity spells are unable to remove the threat of default: A significant share of such spells ends by a default. In periods of low productivity, the returns to austerity may be so low that the government instead opts for a very lenient fiscal policy, incurring fiscal deficits during a default crisis. An even larger share of such spells ends by a default. The preferred remedy of economies with high tax enforcement, i.e., mild fiscal consolidations, is never used by economies with low tax enforcement. These findings illustrate how imperfect tax enforcement may constrain the set of feasible fiscal policies during default crises. They may justify the polarized debate on recovery, some policy makers advocating for extreme austerity with others promoting expansionary fiscal policies.

The impact of dynamic distortions through the size of the informal economy is not qualitatively different from that of more standard fiscal multipliers. Its quantitative implications is however very different in economies with imperfect tax enforcement. The standard behavioral response to tax policy is one order of magnitude lower

\footnotetext{
${ }^{4}$ The degree of tax enforcement in the model is jointly characterized by the distribution of returns in the informal sector and the level of complementarities in the formal sector. Consequently, it relates to the production technology rather than a tax collection technology. In practice, economies may also differ along the latter dimension, a possibility that we ignore.
} 
than that implied by tax evasion, and is insufficient to explain the occurrences of extreme austerity spells. Moreover, standard distortions are quite comparable across economic environments, and are thus unable to generate the observed differences in fiscal dynamics across countries. ${ }^{5}$

This paper contributes to different strands of the literature. We contribute to the literature on sovereign default and limited commitment (Eaton and Gersovitz, 1981; Arellano, 2008). As in Arellano (2008), we assume market exclusion upon default, and default mostly occurs in bad times. In contrast with the two previous contributions, however, we explicitly model fiscal policy as a distortionary instrument which affects the future cost of raising tax revenues. One novelty of our approach, compared to numerous contributions (see for instance Aguiar et al., 2005; Cuadra et al., 2010; Bi, 2012; D'Erasmo and Mendoza, 2013; Arellano and Bai, 2016), is that distortions induced by fiscal policy do not only affect the contemporaneous choice of fiscal policies, but also future repayments and the debt pricing schedule. ${ }^{6}$ Some economies are at risk of falling into a tax evasion overhang. ${ }^{7}$ This mechanism is what generates periods of extreme austerity.

Our framework rationalizes the use of pro-cyclical fiscal policies in developing economies. In the model, the government generally adopts a counter-cyclical fiscal policy which maintains reasonably low debt levels in most future states of the World. However, in catastrophic states, economies often implement very costly pro-cyclical fiscal policies, a paradox that has been highlighted and discussed in the recent literature. (Kaminsky et al., 2004; Ilzetski and Vegh, 2008; Vegh and Vuletin, 2015). Many theoretical mechanisms have been discussed to explain this observation. ${ }^{8}$ Our approach relies on limited commitment: the proximity to a "debt ceiling" is what drives some economies to implement pro-cyclical fiscal policies (Aguiar et al., 2005; Cuadra et al., 2010), which, in our framework, are even more costly.

A key contribution is to provide novel stylized facts on the fluctuations in tax

\footnotetext{
${ }^{5}$ The elasticity of tax receipts $t$ to tax rates $\tau$, which determines the slope of the Laffer curve and indirectly the magnitude of distortions, can be written as a function of the elasticities of output $y$ and tax compliance $\gamma$, i.e., $\partial \ln (t) / \partial \ln (\tau)=1+\partial \ln (y) / \partial \ln (\tau)+\partial \ln (\gamma) / \partial \ln (\tau)$. We find that differences in the latter is what drives variation in the dynamics of fiscal policies across institutional environments.

${ }^{6}$ Recently, Mendoza and Yue (2012) and Bocola (2016) have studied how default itself may distort the domestic economy through the collapse of the banking sector, thereby providing some additional commitment for governments to repay.

${ }^{7}$ Dovis et al. (2015) develops a model in which a similar dynamic component affects the future cost of fiscal policies. Their framework relies on inequality across domestic citizens as the endogenous state variable affecting default risk, thereby describing an inequality overhang.

${ }^{8}$ See Kaminsky et al. (2004) for instance on international capital flows, or von Hagen and Harden (1995); Aaron Tornell (1999); Alesina et al. (2008) for explanations based on the redistribution effect of increasing taxes; the competition among taxpayers to receive the proceeds from the positive shock; or the desire to limit rents that politicians could capture.
} 
compliance. We construct a measure of tax compliance for many developed and developing countries in the post-war period. ${ }^{9}$ Our measure uses two different sources, i.e., taxes as received by the government and the reported consumption of goods at a highly disaggregated level, and capture any discrepancies between these two sources. We show that tax compliance is, in some countries, very volatile, strongly counter-cyclical and very responsive to tax rates. These findings may help rationalize differences in estimates of fiscal multipliers across environments and fiscal policy tools (Alesina and Ardagna, 2009; Romer and Romer, 2010; Favero et al., 2011; Auerbach and Gorodnichenko, 2012; Ilzetzki et al., 2013; Alesina et al., 2015).

Our paper closely relates to the literature having investigated the role of corruption or tax evasion in recent debt crises (see Pappa et al., 2015; Pappadà and Zylberberg, 2017). In Pappa et al. (2015), tax hikes increase the incentives to conceal part of the activity and produce in the less productive informal sector, thus increasing output and welfare losses. This mechanism affects the size of the fiscal multiplier and explain the failure of the recent consolidation plans in Greece, Italy, Portugal and Spain. One addition of the present analysis is to consider the impact of such mechanism on sovereign default.

One key ingredient of our model is imperfect tax enforcement, which induces frictions in transfers between the government and the households. The modeling of endogenous tax compliance borrows from the literature on shadow economies with dual technology (Rauch, 1991; Enste and Schneider, 2000; Straub, 2005). An important aspect of our modeling is that there exist complementarities across producers of the formal sector; taxes thus strongly reduce total output and not only available income. Such pattern could be generated by spillovers across production units through innovation, but could also be related to increasing returns to tax compliance. A recent contribution, Pomeranz (2015), presents evidence in favor of enforcement spillovers in VAT, a feature that would be captured by complementarities across producers of the formal sector.

The remainder of the paper is organized as follows. In Section 2, we describe our data sources and how we construct measures of tax compliance. We then present some stylized facts. Motivated by these observations, we introduce a model of sovereign debt augmented with imperfect tax enforcement and dynamic distortions in Section 3. Section 4 derives the qualitative predictions of the model, while Section 5 presents the quantitative analysis. Finally, Section 6 briefly concludes.

\footnotetext{
${ }^{9}$ We extend the dataset and the results of Pappadà and Zylberberg (2017). In particular, we analyze the volatility of VAT compliance, and its determinants beyond the volatility in tax rates.
} 


\section{Data}

In this section, we describe the construction of a tax compliance indicator based on Value-Added Taxes (VAT), and provide some descriptive statistics on the dynamics of taxes and tax compliance. We then discuss novel stylized facts: tax compliance is differentially volatile across countries; the differential volatility is explained by differential elasticities to the economic cycle and to tax rates. In countries with high volatility, tax compliance strongly responds to changes in economic conditions and the response is persistent.

\subsection{A measure of tax compliance}

To measure tax compliance, we rely on a simple flat tax, the Value-Added Tax, which - as will be shown later - is the preferred instrument to adjust fiscal policy to economic fluctuations. Our measure of tax compliance compares tax receipts to expected receipts as predicted by tax rates and actual expenditures. Letting $t_{i, t, c}$, $\tau_{i, t, c}$ and $c_{i, t, c}$ denote VAT revenues, VAT rate and consumption of good $i$ in year $t$ and country $c$, the measure of VAT compliance is defined as:

$$
\gamma_{t, c}=\frac{\sum_{i} t_{i, t, c}}{\sum_{i} \tau_{i, t, c} c_{i, t, c}} .
$$

The gap between tax revenues and expected tax revenues, as captured by the distance between $\gamma_{t, c}$ and 1 , reflects imperfect tax enforcement from tax authorities. ${ }^{10}$ The measure accounts for possible changes in consumption patterns $c_{i, t, c}$ as a response to differential tax rates across goods: Fluctuations in tax compliance can only arise from changes in tax compliance within good categories.

We use distinct data sources for tax revenues and reported consumption for 48 disaggregated good categories between 1979 and 2013 in about 40 countries. ${ }^{11}$ We observe total VAT receipts $\sum_{i} t_{i, t, c}$ in national accounts. We use annual household expenditure surveys to create actual consumption in each sub-category of good. The information in household surveys comes from the purchaser side thereby alleviating potential under-reporting for undeclared transactions. We also extract from the European Commission documentation and national sources the different tax rates and we reference the types of goods (at the 2-digit level) that are subject to these rates for each country/year. Categories like medical services, international public

\footnotetext{
${ }^{10}$ Such measure cannot shed light on the nature of tax leakages, whether they come from informal exemptions, corruption of tax authorities or non-cooperative tax evasion from agents.

${ }^{11}$ We rely on OECD and Eurostat and their harmonized 48 COICOP (Classification of Individual Consumption by Purpose) sub-categories of goods.
} 
transport, basic food products or cultural services are subject to reduced rates or exemptions and these categories are frequently updated.

There exist some adjustments that we need to implement in order to get as close as possible from the theoretical benchmark. First, we are interested in the shortterm fluctuations of the measure $\gamma_{t, c}$, and we cannot allow for "high-frequency" measurement error. Tax reforms are often implemented during the year, while national accounts are closed at the end of each period, i.e., year or quarter. As tax rates are changed during the course of the year, we construct the annual effective tax rate by weighting each tax rate by the consumption observed during its spell. When consumption could not be observed at a higher frequency than the period, we construct the annual effective tax rate by weighting each tax rate with the time during which it was enforced.

Second, some tax reforms do not modify rates but also modify the category of goods that are subject to the different tax regimes. For instance, for countries entering in the European Union, art galleries would pass from category 1 to category 3. In such instances, we redefine our tax base correctly when our decomposition in the different categories allows us to observe exactly the category that has been modified. When, instead, we do not observe consumption in art galleries, but we observe consumption for a larger category ("cultural goods"), we reconstruct a synthetic tax base for art galleries and the other cultural goods by considering the average share of art galleries among cultural goods over the period. Along the same lines, VAT can be collected for all registered firms or there may exist a minimum threshold. In the case of a reform affecting this threshold, we recreate the new tax base by subtracting the average share of value added created by firms below the threshold. A more precise description of our adjustments for changes in categories and exemptions, and an estimation of the measurement error that we introduce with our corrections are available in the Appendix.

Third, some reforms modify the tax environment without modifying the tax rates per se. For instance, adopting online forms considerably simplifies the registration process. We collect this information and later control for any such reforms in our empirical specifications.

\subsection{Descriptive statistics}

In this section, we provide summary statistics for (i) the composition of tax revenues and its variation across years, (ii) the cyclicality of the different tax instruments, and (iii) the measure of VAT compliance.

First, we calculate the within-country standard deviation of tax compliance be- 
tween 1995 and 2013, as a proxy for the overall volatility of tax compliance. Figure 1 plots these volatilities, and compare them to another measure of imperfect tax enforcement, i.e., the size of the informal sector (2005-2012) as computed in Schneider and Enste (2013). We find wide disparity in the volatility of tax compliance across countries, and, interestingly, this disparity is only partly reflecting differences in the size of the informal sector. While there is a positive correlation between the two measures, some countries with a small informal sector markedly differ along the fluctuations in tax compliance. In what follows, we define two groups of countries: those with above-median standard deviation of tax compliance (red in Figure 1) and those with below-median standard deviation (blue in Figure 1). ${ }^{12}$

Second, we report summary statistics for tax revenues, tax rates and tax compliance in Table 1. For each variable, we display the sample average, the average in each of group of countries, and we generate two indicators of within-country fluctuations: the coefficient of variation to capture overall volatility, and the correlation with the cycle to estimate its cyclical component.

The decomposition of tax revenues between VAT, income taxes and corporate taxes (respectively $32 \%, 28 \%$ and $15 \%$ ) is similar in both groups of countries. The volatilities of VAT and income taxes are similar in magnitude, and they both appear to be orthogonal to economic conditions. However, variation in tax revenues may provide a biased image of fiscal policy over the cycle, and we also analyze the sensitivity of tax rates to economic conditions. While tax revenues are mostly acyclical or mildly pro-cyclical, the rates for VAT, income taxes, and corporate taxes are counter-cyclical and quite strongly so for VAT. Even though VAT contribute less to global variations in tax revenues than the income tax, its influence on fiscal policy along the economic cycle is large.

To reconcile the acyclicality of VAT revenues with the sharp counter-cyclicality of effective rates, we need to analyze fluctuations in VAT compliance. In our sample of countries, VAT compliance is 0.87 on average, which is arguably quite high - maybe due to the over-representation of rich economies. In the sample of high-volatility economies, tax compliance is lower, around 0.84, reflecting that fluctuations in tax compliance mostly occur in economies with sizable tax evasion. The within-country variations in tax compliance are of the same order of magnitude as variations in revenues. However, and in contrast to revenues, compliance is markedly pro-cyclical

\footnotetext{
${ }^{12}$ The high-volatility group is composed of the following countries: Bulgaria, Canada, Colombia, Cyprus, Czech Republic, Greece, Hungary, Ireland, Italy, Japan, Luxembourg, Macedonia, Poland, Portugal, Romania, Russia, Slovakia, Slovenia, South Africa and Spain. The low-volatility group is composed of the following countries: Australia, Austria, Belgium, Chile, Denmark, Estonia, Finland, France, Germany, Israel, Malta, the Netherlands, New Zealand, Norway, Serbia, Sweden, Switzerland and the United Kingdom.
} 
(correlation of .32) thereby counteracting the counter-cyclicality of tax rates. Overall, the cyclicality of tax revenues reflects two opposing forces: a counter-cyclical tax rate (i.e., a pro-cyclical fiscal policy), and a pro-cyclical tax compliance. Recessions are associated with high tax rates, and high tax evasion.

These summary statistics provide some support for the use of Value-Added Taxes to construct of a measure of tax evasion. VAT is of interest not only because, as a rather simple tax instrument, it allows for the construction of a credible measure of tax evasion across countries and over time, but also because it is the preferred tax instrument in order to adjust to economic conditions and the associated distortions appear to be counter-cyclical.

\subsection{Stylized facts}

In this section, we uncover an important, yet overlooked, characteristic of tax compliance: it fluctuates markedly with economic conditions. We estimate the following baseline specification:

$$
\Delta \ln \gamma_{t c}=\varepsilon_{z} \Delta z_{t c}+\beta \mathbf{X}_{t c}+\delta_{t}+\mu_{c}+\varepsilon_{t c}
$$

where $t$ indexes the year and $c$ stands for the country. $\Delta \ln \gamma_{t c}$, our dependent variable, is the annual percentage change in VAT compliance. $z_{t c}$ is the the annual percentage change in (HP-filtered) GDP per capita. The vector $\mathbf{X}$ includes timevarying controls, such as the existence of concurrent tax reforms, changes in the sectoral decomposition of economic activity, changes in government expenditures and changes in trade (the ratio of exports and imports over GDP). $\mu_{c}$ captures country-specific trends in tax compliance and $\delta_{t}$ a year fixed-effect. $\varepsilon_{t c}$ is the error term with standard errors clustered at the country level.

Cyclicality of tax compliance Panel A of Table 2 reports estimates for the elasticity $\varepsilon_{z}$ : the elasticity is significantly positive and quite large (0.40). As shown in columns 2, 3 and 4, the correlation is robust to the addition of controls (sectoral composition in column 2 and trade in column 3 and government expenditures in column 4). An increase of one percent in GDP per capita is associated with an increase of 0.4 percent in tax compliance (about 0.3 percentage points).

We then estimate two differential elasticities $\varepsilon_{z}$ in the two groups of countries separated by their position with respect to the median volatility. To this end, we add an interaction between $\Delta z_{t c}$ and a dummy for being in the high-volatility group, and we report the results in Panel B of Table 2. The coefficient before $\Delta z_{t c}$ is the 
average elasticity in the low-volatility group (between 0 and .08) while the sum of this coefficient and the one before the interaction term is the average elasticity in the high-volatility group (about 0.65). The sharp difference between the two groups is striking: tax compliance is acyclical the low-volatility group while economic conditions explain about $10 \%$ of the overall volatility in tax compliance in the highvolatility group. ${ }^{13}$

Sensitivity of tax compliance to tax rate We replicate the two previous specifications and replace the explaining variable $\Delta z_{t c}$ by the annual percentage change in VAT standard rates $\Delta \tau_{t c}$ such as to capture the elasticity of tax compliance to tax rates, $\varepsilon_{\tau}$, in both groups of countries (controlling for the previous fluctuations in output). ${ }^{14}$ The results, presented in Panels A and B of Table 3, show that there is a strong negative correlation between the dynamics of tax rates and tax compliance. The elasticity of tax compliance to tax rates is around -0.35 on average but there is a difference between the two groups of countries. In our preferred specifications (columns 2 and 3), the elasticity is more than four times lower for the low-volatility group -0.10 than for the high-volatility group -0.45 . Economies with volatile tax compliance strongly respond to economic conditions but also exhibit significantly higher behavioral response to tax hikes.

We also explore within-country heterogeneity in the elasticity of tax compliance to tax rate. Two economies with similar fundamentals may respond differently to a tax hike, depending on economic conditions. We define three dummies for periods of low output based on HP-filtered GDP growth per capita (1: negative HP-filtered growth, 2: 25\%-lowest HP-filtered growth, 3. below-median HP-filtered growth), and interact them with $\Delta \tau_{t c}$ in the previous specification. The results, presented in Table 4, show that the elasticity of tax compliance to tax rate is around 0.29 in normal conditions, and around $0.45-0.47$ in recessions. While the difference between these two coefficients is not significant, they indicate that fiscal consolidationswhich are mostly implemented in downturns - are particularly distortionary when the returns to economic activity are already low.

Persistence of tax compliance In Table 5, we quantify the persistence of tax compliance over time. We regress tax compliance in period $t$ on its lag, with year-

\footnotetext{
${ }^{13}$ We show in Appendix Table A1 that the distinction between the two groups of economies does not overlap with a more general divide "developed" / "developing" economies as adopted in Vegh and Vuletin (2015).

${ }^{14}$ We provide a sensitivity analysis in Appendix Table A2 with the effective VAT rates instead of the standard rate. This specification accounts for changes in exempted categories, reduced and super-reduced rates as well.
} 
and country-fixed effects, GDP growth and yearly changes in industrial composition as covariates, and we instrument the lagged tax compliance by lagged changes in tax rates. Our findings indicate that tax compliance is quite persistent over timethe empirical model corresponds to an $\mathrm{AR}(1)$ process with coefficient 0.70 . The dynamics of tax compliance will be an important aspect of the theory, as distortions implied by an episode of fiscal consolidation will have further repercussions on future tax collection.

Interpretation We have shown that (i) tax compliance is volatile, co-moves with fiscal policies, and (ii) there is a large heterogeneity across countries. Our theoretical interpretation is that economic agents face a trade-off between declared and undeclared activity. In economies with imperfect tax enforcement (i.e., the high-volatility group), changes in taxes tilt the trade-off faced by agents and a number of these agents switch their economic activity from or to the informal sector. This response is, in nature, not that different from the more standard behavioral response in which economic agents adjust their labor supply. It differs, however, along two important aspects: (i) the impact of the tax compliance channel on the elasticity of tax revenues to tax rate is one order of magnitude larger than the standard behavioral response, and (ii) there may exist distortions specific to production in the informal sector, for instance arising from positive spillovers of transparency. There are enforcement spillovers in Value-Added Taxes, and the relative returns to the formal sector depend on the size of the declared activity (Pomeranz, 2015). Credit, innovation, or the structure of the production chain may also be affected by the size of the informal sector, and in turn modify the returns to the formal sector. These channels would generate positive externalities to tax compliance. These externalities induce an inefficient decentralized allocation, with an inefficiently low tax compliance, and changes in the structure of taxes would modify the extent to which the economic activity is distorted toward the informal sector. In what follows, we add such tax compliance channel in a simple model of sovereign debt where the constraint induced by the response of the economy to distortionary tax instruments interacts with the constraint induced by the limited commitment to repay. The objective of the model is to rationalize the dynamics of fiscal policies and their impact on default risk. The empirical estimates will be used to discipline the calibration of the production side of the economy. 


\section{A model of a small open economy}

This section develops a model of a small open economy with a representative household and a government. The model embeds production with different technologies in an otherwise standard framework à la Eaton and Gersovitz (1981) where a benevolent government with limited commitment issues debt on behalf of the household.

The predictions of the model derive from the interaction of two frictions. There is imperfect tax enforcement: transfers from/to the household are made through a distortionary instrument that affects the cost of raising revenues in the future. There is limited commitment from the government to reimburse its debt, and default risk limits the government capacity to transfer consumption from the future to the present. Consider a government willing to reduce debt. An increase in tax rates raises the distortions associated with future tax collection. Bondholders revise downward their expectations on future payments that could be sustained by the government. The increase in tax rates decreases debt through a direct effect but affects the borrowing capacity of an economy through this indirect channel.

The theoretical predictions of the model do not rely on the exact modeling of distortions associated with imperfect tax enforcement as long as these distortions are persistent and interact with limited commitment. We rely on a simple model where entrepreneurs make a (staggered) choice between an informal technology and a formal technology and there are production complementarities in the formal sector.

\subsection{Preferences and technology}

The economy is populated by a continuum of infinitely lived households of measure one. Letting $c_{t}$ denote her consumption at time $t$, the representative household in this economy maximizes expected utility as given by:

$$
E_{t} \sum_{s=t}^{\infty} \beta^{s-t} u\left(c_{s}\right),
$$

where $\beta<1$ denotes the discount factor and $u(\cdot)$ represents the period utility function, which satisfies $u^{\prime}(\cdot)>0$ and $u^{\prime \prime}(\cdot)<0$. Since all households are identical, we refer to them throughout as the representative household. In what follows, we may drop time indices for the sake of exposure.

There are two types of agents who populate households. Each household is composed of a unit mass of entrepreneurs who hold one unit of an investment good in each period, and a unit mass of final good producers. There is perfect redistribution within each household such that all agents consume the same in each period. 
The consumption good can be produced with two technologies. First, it can be assembled by final good producers using investment goods. We assume that there are many varieties of such investment goods $y_{i}$ and there are complementarities between the investment goods $y_{i}$ when they are used as factors of production for the consumption good. ${ }^{15}$ Final good producers assemble investment goods $y_{i}$ using the following CES technology,

$$
y=z\left(\int_{0}^{1} y_{i}^{\phi} d i\right)^{\frac{1}{\phi}},
$$

where $\phi<1$ captures production complementarities and $z$ is a technology shock which follows a Markov process. We assume that the final good producers are fully transparent. This technology represents the formal sector of our economy.

Second, the final good can be directly produced by entrepreneurs. Entrepreneurs can transform their investment unit into the final good using a private technology with unobservable constant return $R$. We assume that $R$ is known to the entrepreneur only and is distributed along a continuous probability distribution $H($.$) .$ This technology is not observable to the government and represents the informal sector of our economy. ${ }^{16}$ We assume that markets for investment goods and the final good are perfectly competitive.

Moreover, there are rigidities and technological choice is staggered over time, in the manner of Calvo (1983). In each period, there is an idiosyncratic draw determining whether an entrepreneur is allowed to change her technology. With probability $1-\theta$, the entrepreneur can choose and either (i) adopt the formal technology, produce an investment good and sell her unit to the final good producer, or (ii) adopt the private technology. With $\theta=0$, this choice would be completely flexible across periods and the contemporary choice does not commit the entrepreneur in the future.

There is a benevolent government whose objective is twofold. First, in each period, the government needs to produce and finance a public good whose cost $g_{t}$ is exogenous and subject to shocks, following a Markov process. Second, the government maximizes the welfare of the representative household by issuing debt and purchasing assets on its behalf: the household's borrowing and saving are done exclusively through the government. In order to finance the public investment and

\footnotetext{
${ }^{15}$ These complementarities can capture spillovers across transparent firms through innovation; complementarities along the production chain; (tax) enforcement spillovers along the production chain. Any mechanism, in which the relative return to the formal technology increases with the mass of producers adopting this technology, could be captured by this structure of complementarities.

${ }^{16}$ The hypothesis that one technology is fully informal while the other one is fully transparent can be relaxed. There is a need for the technology in which there exist complementarities in production to be relatively more transparent.
} 
transfer from and to the household, we assume that the benevolent government can only levy indirect taxes $\tau$ on final output. ${ }^{17}$

\subsection{Financial markets}

We assume that the economy is small relative to the international financial market, and that the government can issue and trade one-period bonds on these markets. The international financial market is willing and able to purchase any asset that yields an expected return at least as high as $\rho$.

The government stabilizes the consumption of the representative household by issuing debt and purchasing assets on its behalf. The debt is financed either through taxation on the household itself or through new debt issue. The government has imperfect commitment and may default on its obligations. Let $b_{t+1}$ and $q_{t+1}$ respectively denote the amount and price of debt issued by the government at time $t$, and let $D_{t} \in\{0,1\}$ denote the decision to default on previous obligations. If $t_{t}$ denotes total indirect taxation levied by the government at time $t$, the resource constraint for the government is:

$$
\left(1-D_{t}\right) b_{t}-q_{t+1} b_{t+1}=t_{t}-g_{t}
$$

We suppose that there are two sources of punishment which gives some (limited) commitment to the government. As in Arellano (2008), there is an exclusion from the international market following a default and reintegration is stochastic and occurs with probability $\nu$ in each period. We further assume that, during market exclusion, there is an exogenous default cost $\delta$ that is incurred by the household directly. This cost captures the fact that the domestic intermediation sector may be affected by a default through a capital flight from financial investors (Mendoza and Yue, 2012). Since transfers from the government are made through a distortionary instrument, it is not innocuous to assume that the default cost is paid by the household. A government with distortionary tax instruments has incentives to default because a default is then a relatively efficient way to redistribute to the representative household.

In order to solve for the equilibrium of the economy, we need to understand how the government makes savings and investment decisions. We turn to these next.

\footnotetext{
${ }^{17}$ We use an indirect tax to match the empirical estimates, but any distortionary instrument with different impact on returns across technologies would generate the same qualitative results.
} 


\subsection{Timing of actions and equilibrium}

We now specify the timing of actions within each period. At the beginning of each period, the aggregate shocks $z_{t}$ and $g_{t}$ are revealed and perfectly observed by all agents. If the government is excluded from international financial markets, a reintegration draw takes place. The government then decides to repay or default on its past obligations $b_{t}$, and commits to an indirect taxation rate $\tau_{t}$. Production takes place and taxes are paid by agents. International financial markets open, and sovereign bonds are traded. Finally, households consume.

In order to characterize the equilibrium of this economy, we need to explore the dynamic optimization problem of entrepreneurs, the dynamic optimization problem of the government and how investors price sovereign debt. We turn to these separate programs next.

Entrepreneurs and final good producers We first describe the (static) program of final good producers. In each period, these producers take prices $p_{i}$ of each intermediate good variety as given and maximize:

$$
\max _{y_{i}}\left\{z(1-\tau)\left(\int_{0}^{1} y_{i}^{\phi} d i\right)^{\frac{1}{\phi}}-\int_{0}^{1} p_{i} y_{i} d i\right\} .
$$

The resulting demand is characterized by the following equation:

$$
z(1-\tau) y_{i}^{\phi-1}\left(\int_{0}^{1} y_{i}^{\phi} d i\right)^{\frac{1}{\phi}-1}=p_{i} .
$$

We now focus on the program of entrepreneurs. In each period, there is an idiosyncratic draw determining whether an entrepreneur can set her technology. With probability $1-\theta$, the entrepreneur can adopt the formal technology and sell to final good producers, or adopt the private technology. With probability $\theta$, the entrepreneur keeps the same technology as in period $t-1$. The aggregate transparency, $\gamma_{t}$, defined as the share of entrepreneurs operating in the formal sector, verifies the following dynamics:

$$
\gamma_{t}=(1-\theta) \gamma_{t}^{*}+\theta \gamma_{t-1},
$$

where $\gamma_{t}^{*}$ is the share of entrepreneurs deciding to operate in the formal sector among those entrepreneurs with the opportunity to modify their technology.

The decision of entrepreneurs depends on the returns to each technology in future 
states of nature. Formally, entrepreneurs compare the returns in the formal sector:

$$
\sum_{k=0}^{\infty} E_{t} \delta_{t+k} r_{t+k}
$$

where $r_{t+k}=\left(1-\tau_{t+k}\right) z_{t+k} \gamma_{t+k}^{\frac{1}{\phi}-1}$ is the expected price for one unit of variety $i$ in the formal sector in period $t+k, \delta_{t+k}=\beta^{k} \theta^{k} \frac{u^{\prime}\left(c_{t+k}\right)}{u^{\prime}\left(c_{t}\right)}$ is the (effective) discount factor between period $t$ and period $t+k$, and $\theta^{k}$ is the probability for the decision in period $t$ to be still relevant in period $t+k$, to the returns in the informal sector:

$$
\sum_{k=0}^{\infty} E_{t} \delta_{t+k} R
$$

where $R$ is the unobserved individual return to the private technology.

Among entrepreneurs with the opportunity to modify their technology, the share of them adopting the formal technology should be equal to the ones with sufficiently high returns in the formal sector, i.e.,

$$
\gamma_{t}^{*}=H\left[\frac{\sum_{k=0}^{\infty} E_{t} \delta_{t+k} r_{t+k}}{\sum_{k=0}^{\infty} E_{t} \delta_{t+k}}\right] .
$$

We can then replace $\gamma_{t}^{*}$ using the equation characterizing aggregate transparency, and use a first-order approximation, which brings: ${ }^{18}$

$$
R_{t}=(1-\theta \beta) r_{t}+\theta \beta E_{t} R_{t+1},
$$

where $R_{t}=H^{-1}\left(\frac{\gamma_{t}-\theta \gamma_{t-1}}{1-\theta}\right)$ denote the level of unobserved return in the informal sector for which an individual is indifferent between the two technologies. Equation (3) describes the (sluggish) dynamics of aggregate transparency, which governs distortions on the production side of the economy, as a function of returns to the formal sector.

Households Households make no saving or borrowing decisions in our economy. Once they receive the output net of taxes $w$, their consumption is given by

$$
c=w
$$

\footnotetext{
${ }^{18}$ We restrict our analysis to distributions $H$ with a support such that Equation (3) implicitly defines a unique solution $\gamma_{t}$ as a function of $\left(\gamma_{t-1}, \gamma_{t+1}, r_{t}\right)$. The condition is made explicit in the online Appendix.
} 
In order to smooth consumption, the government needs to smooth output net of taxes through the level of these indirect taxes.

Bond prices Investors are ready to buy any bonds in period $t$ as long as these bonds guarantee at least $\rho$ in expectations in period $t+1$. The bond price schedule verifies

$$
q_{t+1}=\rho^{-1} E_{t}\left[1-D_{t+1}\right]
$$

Bond prices range between 0 , when default is expected with certainty next period, and $\rho^{-1}$.

Government The government is assumed to be benevolent and to maximize the welfare of consumers in each period $t$ by choosing the levels of taxes $\tau_{t}$, public savings $b_{t+1}$ and default decisions $D_{t}$, subject to the budget constraint (2), the endogenous response of entrepreneurs, as characterized by Equation (3), and the bond price schedule (4).

We are now ready to define a recursive equilibrium of our economy, and shed light on the main trade-off underlying government decisions.

\section{Recursive equilibrium and dynamic properties}

In this section, we define the equilibrium characterizing the economy in a recursive form, and provide some intuitions behind the main mechanisms at play in the model.

\subsection{Recursive equilibrium and default sets}

Our environment is one in which entrepreneurs and the government do not interact cooperatively over time: entrepreneurs form beliefs about future government decisions in order to set their current technology. As we suppose limited commitment towards foreign investors, we also assume that the government does not have any commitment device towards domestic entrepreneurs about its future choices. The set of equilibria that will be considered are thus Markov perfect equilibria in which agents perfectly observe a common state vector.

Let us define this state of the economy. Given the assumptions that (i) productivity and expenditure shocks follow a Markov process, (ii) technological choices are staggered in the manner of Calvo (1983), (iii) market reintegration is idiosyncratic, the following quantities fully characterize the economy at the beginning of period $t$ : the state of the economy with respect to international markets, $h_{t} \in\{A, E\}$, where $A$ is 'access' and $E$ is 'exclusion'; the inherited asset position $b_{t}$; the inherited 
state of technological choices $\left(\gamma_{t-1}, R_{t-1}\right)$; and current productivity $z_{t}$ and public expenditures $g_{t}$. For convenience, let $s_{t}=\left(b_{t}, \gamma_{t-1}, R_{t-1}, z_{t}, g_{t}\right)$ denote the state of the economy, except from access to international bond markets.

A recursive Markov perfect equilibrium is given by a sequence of government debt $\left\{b_{t+1}\right\}$, transparency and indifference points $\left\{\gamma_{t}, R_{t}\right\}$, default decisions $\left\{D_{t}\right\}$ and bond price schedule $\left\{q_{t+1}\right\}$ satisfying the following conditions in all periods and histories:

Definition 1. In each period $t$, the government debt and default decisions maximize the representative household's welfare, given the state $\left(h_{t}, s_{t}\right)$ of the economy, and subject to the period budget constraint (2) and the bond price schedule (4). The entrepreneurs maximize their profits, and Equation (3) defines the dynamics of transparency, tax receipts and output.

The government value function in period $t$ is,

$$
v\left(\mathbf{s}_{\mathbf{t}}\right)=\mathbb{1}_{h_{t}=A} \cdot v_{A}\left(\mathbf{s}_{\mathbf{t}}\right)+\mathbb{1}_{h_{t}=E} \cdot v_{E}\left(\mathbf{s}_{\mathbf{t}}\right),
$$

where the conditional value functions $v_{A}$ and $v_{E}$ follow the following recursive formulations: ${ }^{19}$

$$
\begin{aligned}
& v_{A}\left(\mathbf{s}_{\mathbf{t}}\right)=\max _{D_{t}, b_{t+1}, \gamma_{t}, t_{t}}\left\{u\left(\mathbf{c}_{\mathbf{t}}\right)+\beta\left(1-D_{t}\right) E_{t} v_{A}\left(\mathbf{s}_{\mathbf{t}+\mathbf{1}}\right)+\beta D_{t} E_{t} v_{E}\left(\mathbf{s}_{\mathbf{t}+\mathbf{1}}\right)\right\}, \\
& v_{E}\left(\mathbf{s}_{\mathbf{t}}\right)=(1-\nu)\left[u\left(c_{t}(1-\delta)\right)+\beta E_{t} v_{E}\left(\mathbf{s}_{\mathbf{t}+\mathbf{1}}\right)\right]+\nu \max _{b_{t+1}, \gamma_{t}, t_{t}}\left\{u\left(c_{t}\right)+\beta E_{t} v_{A}\left(s_{t+1}\right)\right\},
\end{aligned}
$$

subject to Equations (2), (3), (4) and $R_{t}=H^{-1}\left(\frac{\gamma_{t}-\theta \gamma_{t-1}}{1-\theta}\right)$.

As in Eaton and Gersovitz (1981) or Arellano (2008), the decision to default can be fully described by a default set $D(b, \gamma, R)$, which is a set of states of nature $(z, g)$ under which the government prefers to default, as a function of the endogenous state variables $(b, \gamma, R)$. The recursive equilibrium of this economy is then defined as a set of price functions for bonds, policy functions for the government including $D(b, \gamma, R)$ such that (i) the government policy functions solve the government problem taking as given price functions for bonds and the dynamics of transparency as defined by Equation (3), and (ii) bond prices reflect the default probabilities implied by the policy functions $D(b, \gamma, R)$.

\footnotetext{
${ }^{19}$ Without market access, the government makes no decisions because the period tax rate, and thus the level of transparency and the indifference thresholds, are pinned down by the budget constraint $t_{t}=g_{t}$.
} 
These default sets defined above satisfy the following monotonicity property: default sets are monotonous in inherited debt. If $b_{1}<b_{2}$, then $D\left(b_{1}, \gamma, R\right) \subseteq$ $D\left(b_{2}, \gamma, R\right)$. The proof of this property is immediate by contradiction. Assume that there exists a state of nature $(z, g)$ such that $(z, g) \in D\left(b_{1}, \gamma, R\right)$ but $(z, g) \notin$ $D\left(b_{2}, \gamma, R\right)$. The maximum utility reached after a default is independent of current debt $b_{1}$ or $b_{2}$. By contrast, the maximum utility that can be reached with reimbursement depends on current debt. Let $b^{\prime}, \gamma^{\prime}$ and $R^{\prime}$ denote the chosen debt level, transparency and indifference threshold conditional on reimbursing for the state $\left(b_{2}, \gamma, R\right)$. We have that $u\left(w\left(b^{\prime}, b_{2}, \gamma, R, z, g\right)\right)+\beta E_{t} v_{A}\left(b^{\prime}, \gamma^{\prime}, R^{\prime}, z^{\prime}, g^{\prime}\right)$ is greater than the value of default because $(z, g) \notin D\left(b_{2}, \gamma, R\right)$ by assumption. However, the utility from reimbursement associated with inherited debt $b_{1}$ and the same targets $\left(b^{\prime}, \gamma^{\prime}, R^{\prime}\right)$ would be $u\left(w\left(b^{\prime}, b_{1}, \gamma, R, z, g\right)\right)+\beta E_{t} v_{A}\left(b^{\prime}, \gamma^{\prime}, R^{\prime}, z^{\prime}, g^{\prime}\right)$ and would be higher than the utility from default because

$$
w\left(b^{\prime}, b_{1}, \gamma, R, z, g\right) \geq w\left(b^{\prime}, b_{2}, \gamma, R, z, g\right)
$$

As a consequence, reimbursement is preferred to default, and $(z, g) \notin D\left(b_{1}\right)$, which contradicts the initial hypotheses.

\subsection{Distortions and fiscal multiplier}

We analyze the static distortions implied by a fiscal consolidation on transparency and total output.

First, letting $\varepsilon_{t}$ denote the elasticity of transparency to tax rate as implied by Equation (3) (estimated to be around -0.3 in Section 2), ${ }^{20}$ the elasticity of transparency to tax receipts, $t_{t}$, verifies

$$
\frac{\partial \gamma_{t}}{\partial t_{t}} \frac{t_{t}}{\gamma_{t}}=\frac{1}{1 / \phi+1 / \varepsilon_{t}} .
$$

The degree of complementarity in the formal sector, $\phi$, determines the extent to which a change in fiscal surplus distorts the allocation of entrepreneurs between the formal and informal sector. Specifically, when spillovers across entrepreneurs are large ( $\phi$ is small relatively to $-\varepsilon_{t}$ ), a change in fiscal surplus has a large effect on the allocation of entrepreneurs. As the tax rate increases, entrepreneurs switch to the less productive (but tax-free) informal sector, which, with complementarities in production, sharply drives down the returns to the formal sector and creates a

\footnotetext{
${ }^{20}$ The reader interested in the derivation of the tax compliance response $\partial \gamma / \partial \tau<0$ may refer to the Appendix.
} 
multiplier effect captured in $1 / \phi$.

A change in the allocation of entrepreneurs across technologies affects consumption $c_{t}=w_{t}{ }^{21}$ One can show that the effect of a change in fiscal surplus on consumption is:

$$
\frac{\partial c_{t}}{\partial t_{t}}=-1+\left[\frac{r_{t}}{\phi}-R_{t}\right] \frac{\partial \gamma_{t}}{\partial t_{t}}
$$

With lump-sum transfers, a change in fiscal surplus would generate a one-to-one loss in consumption and total output would be left unchanged. However, when taxes are distortionary $\left(\partial \gamma_{t} / \partial t_{t}<0\right)$, consumption drops even further and the size of leakages depends upon (i) the shift in the allocation of entrepreneurs between the formal and informal sector and (ii) the difference between the social returns in the formal and informal sectors $r_{t} / \phi-R_{t}$. The degree of complementarity in the formal sector impacts both quantities. When complementarity is high in the formal sector, there are large differences between the social returns in the formal and informal sectors at equilibrium and transparency sharply responds to changes in fiscal surplus. In our model with non-Ricardian households, the previous equation characterizes the size of the fiscal multiplier, which is always greater than 1 .

\subsection{Dynamic properties of the recursive equilibrium}

We describe the dynamic properties of the recursive equilibrium. We first assume full commitment in order to highlight the impact of imperfect tax enforcement alone, and analyze optimal fiscal policies in this setting. We then discuss the dynamics in the absence of any commitment. Finally, we discuss how our mechanism modifies the conclusions of a benchmark model à la Arellano (2008), i.e., with non-distortionary redistribution between the government and households.

Full commitment When the government has perfect commitment, debt price is independent of fiscal policy and the solution to the government program verifies a slightly modified Euler equation, i.e.,

$$
\lambda_{t}=E_{t} \lambda_{t+1}
$$

${ }^{21}$ Output net of taxes $w_{t}$ verifies the following equation:

$$
w_{t}=\left(1-\tau_{t}\right) z_{t} \gamma_{t}^{\frac{1}{\phi}}+\theta \int_{R_{t-1}}^{\infty} x d H(x)+(1-\theta) \int_{R_{t}}^{\infty} x d H(x)
$$


where:

$$
\lambda_{t}=-\frac{\partial w_{t} / \partial \gamma_{t}}{\partial t_{t} / \partial \gamma_{t}} u^{\prime}\left(w_{t}\right)-\beta \frac{1}{\partial t_{t} / \partial \gamma_{t}} E_{t} \frac{\partial v_{A}\left(s_{t+1}\right)}{\partial \gamma_{t}} .
$$

The first term is the marginal utility of consumption weighted by a factor accounting for tax leakages. The second term captures the expected future gains of a marginal increase in aggregate transparency. The leakages implied by taxes depend on the elasticity $\varepsilon_{\gamma}<0$ of transparency to tax rates as follows:

$$
-\frac{\partial w_{t} / \partial \gamma_{t}}{\partial t_{t} / \partial \gamma_{t}}=\frac{1-\frac{1-\tau_{t}}{\tau_{t}} \frac{1-\phi}{\phi} \varepsilon_{\gamma}}{1+\frac{1}{\phi} \varepsilon_{\gamma}}
$$

In addition to the desire to smooth consumption across time and states of natureimplying counter-cyclical fiscal policy—, the government takes into account (i) tax leakages and (ii) future distortions. Given that the capacity to raise tax revenues is pro-cyclical, the elasticity $\left|\varepsilon_{\gamma}\right|$ is larger in bad times and leakages would be higher. The optimal tax rates implemented by the government should be even more counter-cyclical than in a world without distortions, in order to equalize the weighted marginal utility of consumption over time.

No commitment When the government cannot save nor borrow, then it needs to satisfy in each period a balanced budget and

$$
t_{t}=\tau_{t} z_{t} \gamma_{t}^{\frac{1}{\phi}}=g_{t}
$$

which implies, combined with Equation (3), that fiscal policy is pro-cyclical. In stark contrast with the perfect commitment case, the higher the distortions related to tax collection, and the higher the differences between the (high) tax rates in bad times and the (low) tax rates in good times.

Main mechanism As we have seen in the previous two cases, the government implements very different policies when fully constrained or fully unconstrained in international debt markets. We now explain the interaction of our transparency channel with limited commitment in the general case.

A fiscal consolidation affects default risk as follows. While an increase in tax rates leads to higher fiscal surplus, it also lowers the contemporary return $r_{t}$ to the formal sector. Through Equation (3), this affects the indifference threshold between the formal and the informal sector, and thus the number of entrepreneurs operating in the informal sector. With staggered technological choices, this response is persistent and increases the future costs of raising tax revenues. Investors anticipate both the 
decrease in debt levels and the more indirect effect on future tax collection. The latter reduces the gains in fiscal consolidations, and is absent from any benchmark model à la Arellano (2008) with non-distortionary redistribution.

While the previous mechanism is always at work, at least qualitatively, its quantitative relevance sharply depends on fundamentals and the state of the economy. The production technology determines the elasticity of transparency to the return $r_{t}$ in the formal sector. A large elasticity would make fiscal consolidations more distortionary. The probability to set technology influences how contemporary shocks affect future transparency. With fully flexible or fully rigid choices, a fiscal consolidation would have little influence on future transparency, and would not be distortionary in the long-run. Finally, the elasticity of default risk to the future costs of raising tax revenues crucially depends on the debt level. It is only above a certain debt level that the future default sets are not empty.

Our "transparency" mechanism impacts the relative return to fiscal consolidations, and the dynamics of optimal fiscal policies. Following a negative shock to productivity, the government would have the incentives to lower tax rates through three distinct channels. First, the government would be willing to smooth available income to the household. Second, low productivity induces a low indifference threshold between the formal and the informal sectors and thus larger inefficiencies and lower pre-tax income. A lower tax rate would mitigate the drop in indifference threshold. Third, low tax rates would increase the returns to tax rates in the future. Such response would be optimal, but only if debt price is not very sensitive to future debt. When, instead, debt prices markedly respond to future debt, an expansionary policy in bad times would increase debt service thereby mitigating the effect of lower distortions. In states of the economy where both the "debt" and "transparency" channels play a role, current and future tax revenues are not very sensitive to fiscal policy which has three implications: (1) default risk is not very sensitive to fiscal policy, (2) optimal fiscal policy may be (weakly) pro-cyclical; (3) the dynamics of the system is stable. ${ }^{22}$

\section{Quantitative analysis}

In this section, we calibrate the model to match the key facts documented in the empirical section, and we evaluate its capacity to describe the joint dynamics of fiscal policy and default in regions of default risk.

\footnotetext{
${ }^{22}$ We illustrate this argument with a more formal analysis of the dynamics and a phase diagram in Appendix B.
} 


\subsection{Calibration and solution method}

In order to calibrate the model, we proceed as follows. We set all parameters but the ones characterizing the production side of the economy as is standard in models of sovereign defaults (Aguiar and Gopinath, 2006; Arellano, 2008). We then estimate the remaining parameters by matching the following key moments of the steadystate economy: (a) the transparency level, (b) the elasticity of transparency to tax rate and (c) the auto-correlation of transparency. Table 6 lists all parameter values.

We set a yearly discount factor $\beta$ corresponding to a discount rate of $10 \%$. We assume, in contrast with the theoretical section, that the government is more impatient than external investors: the risk-free interest rate is set equal to $5 \%$. We use a Constant-Relative-Risk-Aversion utility function with a parameter $s=2$. We assume that the output cost is $5 \%$ of the steady-state output, and the reintegration probability is set such that the average exclusion length is 20 years. As in Aguiar and Gopinath (2006), we assume that the productivity and spending shocks are highly auto-correlated, and we set the standard deviations of innovation shocks to match the volatility of output and public expenditures in the data. We normalize steady-state productivity $z$ to be equal to 1 , and public expenditures $g$ to be $15 \%$ of output.

The model still requires parameter values for fundamentals governing the production side of the domestic economy. There is no direct empirical counterpart, and we use indirect moments to set these parameters. More specifically, we set a functional form for the distribution of returns $H$ and use a uniform distribution with parameters $a_{1}$ and $a_{2}$. We then set $a_{1}, a_{2}$, the degree of complementarity within the formal sector $\phi$ and $\theta$ such as to match (a) the steady-state transparency:

$$
\gamma=H\left[(1-\tau) \gamma^{\frac{1}{\phi}-1}\right]
$$

(b) the elasticity of transparency at the steady-state,

$$
\frac{\partial \gamma}{\partial \tau}=-\frac{(1-\theta)(1-\theta \beta) \gamma^{\frac{1}{\phi}-1} h\left[H^{-1}(\gamma)\right]}{1+\theta^{2} \beta-(1-\theta)(1-\theta \beta)(1-\tau) \gamma^{\frac{1}{\phi}-2}\left(\frac{1}{\phi}-1\right) h\left[H^{-1}(\gamma)\right]}
$$

and (c) the persistence of transparency at the steady-state,

$$
\frac{\partial \gamma^{\prime}}{\partial \gamma}=\frac{\theta}{1+\theta^{2} \beta-(1-\theta)(1-\theta \beta)(1-\tau) \gamma^{\frac{1}{\phi}-2}\left(\frac{1}{\phi}-1\right) h\left[H^{-1}(\gamma)\right]}
$$

where the steady-state level of taxation verifies $\tau=g / \gamma^{1 / \phi}$. The steady-state and 
volatility of transparency mostly pin down the shape of returns in the informal sector and complementarities in the formal sector, while the persistence of transparency pins down the period probability to reset technology. ${ }^{23}$

The output cost and the reintegration probability command the net present cost of default. With only expenditure shocks, we can derive an approximate expression for this cost. Letting $\alpha$ denote the fiscal multiplier at the steady state of the economy, a simple back-of-the-envelope calculation shows that the default cost is equivalent to a period consumption loss of $\frac{r}{r+\nu}\left[\delta+\frac{s \alpha^{2} \operatorname{Var}(g)}{2 \bar{c}}\right]$ where the first term, $\delta$, is the direct output cost and the second term is the cost induced by risk aversion and volatility in consumption during exclusion. ${ }^{24}$ The net present gain from default is a combination of saved interest payments and the degree to which government fiscal surplus affects household consumption. The period gain from defaulting upon debt $b$ is $\alpha r b$ in consumption terms. The ratio $\frac{2 \delta \bar{c}+s \alpha^{2} \operatorname{Var}(g)}{2 \bar{c} \alpha(r+\nu)}$ is thus a proxy for the maximum debt that could be contracted in the economy; our calibration implies that this maximum debt should be around a quarter of output.

In order to solve the model, we create grids for each of the state variables, and we use cubic spline interpolation to approximate the value functions (Hatchondo et al., 2010) such that the government effectively solves a fully continuous problem. The $\mathrm{AR}(1)$ processes for productivity and public expenditures are however discretized using Tauchen (1986) method.

We solve numerically the model as a fixed point problem. The government does not have commitment on future policy and takes it as given when deciding upon contemporary choices. The problem is solved by iteration and we find the fixed point by iterating over the future behavior of the government and the investor debt pricing schedule. More specifically, we initially set two policy functions $\mathbf{s} \mapsto \gamma(\mathbf{s})$ and $\mathbf{s} \mapsto q(\mathbf{s})$, which characterizes the future transparency choice of the government, as a function of the vector $\mathbf{s}$ of state variables, and future expected default, as a function of contemporary transparency and debt. Given the policy functions $\mathbf{s} \mapsto \gamma(\mathbf{s})$ and $\mathbf{s} \mapsto q(\mathbf{s})$, we solve the dynamic problem of the government through value function iteration. We then update the policy functions $\mathbf{s} \mapsto \gamma(\mathbf{s})$ and $\mathbf{s} \mapsto q(\mathbf{s})$, using the government choice of transparency and default obtained in the previous step, and we iterate until we converge to the fixed point.

\footnotetext{
${ }^{23}$ In Section 2, we have derived few additional empirical moments. These moments will be used as over-identification checks for our calibration.

${ }^{24}$ We have shown in Section 4 that the fiscal multiplier at the steady-state can be written as:

$$
\alpha=1+\frac{1-\phi}{\phi} R \frac{\gamma / t}{1 / \phi+1 / \varepsilon}
$$
}

where $\varepsilon$ is the elasticity of tax compliance to tax rate. 


\subsection{Policy functions}

We first analyze properties of the calibrated model by plotting the government policy functions $\left(b_{t+1}, \gamma_{t}\right)$ and the debt pricing schedule $q_{t+1}$. For the sake of exposure, we display the policy functions as functions of the two main state variables $\left(b_{t}, \gamma_{t-1}\right)$ averaged over the possible realizations for the other state variables (see Figure 2).

We first describe optimal fiscal policy as a function of inherited debt. The relationship between debt $b_{t+1}$ and inherited debt $b_{t}$ is not monotonous. For low levels of debt, the relationship is close to being linear as would be predicted under perfect commitment. For higher levels of debt, however, future debt flattens as a function of inherited debt, and this feature derives from two effects. First, the threat of default constrains government choices. Second, the government sometimes does default and future debt is then reset to 0 . Distortions play a crucial role in this response: with high inherited debt, debt service increases and the government increases tax pressure thereby affecting transparency $\gamma_{t}$. The debt pricing schedule is flat and orthogonal to inherited debt levels for low levels, then decreases steadily for higher debt levels.

Another interesting aspect of optimal fiscal policy is its relationship with inherited transparency, $\gamma_{t-1}$, which captures the effect of dynamic distortions. A higher inherited transparency allows the government to raise taxes with limited behavioral response, and thus magnify the returns to fiscal consolidations. By contrast, low inherited transparency significantly lowers the returns to taxes, and transfers from the household are very costly. Low inherited transparency forces the government to raise tax rates with low returns to such tax hikes: future transparency remains low while debt increases, and default occurrences are then more likely.

The interaction of debt and distortions provides additional insight on the role of the external constraint in shaping optimal fiscal policy. First, low levels of contracted debt flatten the dependence in transparency for default risk. Second, inherited debt sharply affects the impact of dynamic distortions. High levels of contracted debt prevent the government from accumulating even higher levels of debt (the dependence of $b_{t+1}$ in $\gamma_{t-1}$ is low for high levels of $b_{t}$ ). Consequently, high inherited distortions force the government to implement very high taxes in order to limit debt accumulation. These high taxes induce high distortions, and there is high persistence in transparency. Instead, low levels of contracted debt allow the government to insure against inherited distortions, and relieve tax pressure in the economy (the dependence of $b_{t+1}$ in $\gamma_{t-1}$ is high for low levels of $b_{t}$ ). 


\subsection{Moments of the baseline economy}

We now evaluate the ability of the quantitative model to reproduce key empirical moments. The most relevant targeted moment is the sensitivity of transparency to tax rates, which governs the size of the fiscal multiplier. A major untargeted moment is the sensitivity of debt prices to fiscal surplus; this moment is disciplined by the separate effects of debt levels and transparency on default risk in the simulated economy. Results in this section are derived from simulating 100 economies characterized by the same primitives as our baseline calibrated economy, and hit by productivity and expenditure shocks over 1000 periods (years).

Targeted moment Primitives of production are set to replicate how transparency varies with fiscal policy in the data. However, the estimation targets the steady-state semi-elasticity of transparency to tax rate. We use the outcome of our simulation, i.e., 100,000 economy $\times$ year observations, and estimate the average semi-elasticity of transparency to tax rate in the simulated economies affected by shocks. The results are reported in Panel A of Table 7. The model closely replicates this crucial empirical moment: the semi-elasticity of transparency to tax rate is -.393 in the simulated economies, versus -.385 in the data. The large response of the technological choice to fiscal policy translates into a large fiscal multiplier. The latter can be retrieved in the simulated economies by regressing output on tax receipts, instrumented by the expenditure shock. ${ }^{25}$ Our simulated economies exhibit an average fiscal multiplier of 1.33, an estimate which is consistent with the back-of-the-envelope estimate for the steady-state fiscal multiplier (see Section 4).

Untargeted moments We present two main untargeted moments. The first moment is the complement to the semi-elasticity of transparency to tax rate: the semi-elasticity of transparency to output. We run the same specification as in the empirical exercise of Table 2 with the simulated data, and we report the estimates in Panel B of Table 7. The model slightly overshoots: a one percentage increase in output is associated with a 0.52 percentage increase in transparency (versus 0.40 in the data).

The second moment is the relationship between fiscal surplus and default risk, accounting for the non-exogenous timing of fiscal policy. ${ }^{26}$ In the second line of

\footnotetext{
${ }^{25}$ Note that we do not observe purely exogenous shocks on fiscal expenditures in the data, and we cannot provide an empirical counterpart to the simulated measure.

${ }^{26}$ The relationship between fiscal surplus and default risk is a correlation both in the simulated and the actual data, and it slightly differs from causal estimates (see the description of policy functions). Indeed, the government mostly implements fiscal consolidation when the other co-
} 
Panel B, we report the correlation between fiscal surplus and default risk in the simulated economies, and we contrast these estimates with the data. ${ }^{27}$ The correlation between the fiscal surplus and debt prices is small and negative in the data and in the simulations. The model closely replicates the fact that the economy does not really succeed in lowering default risk by increasing the tax burden.

The congruence between fiscal surplus and default risk is disciplined by the conflicting effects of fiscal policy on debt levels and on the size of the informal sector. In order to quantify the separate contribution of the partial dependence of default risk on (i) debt level and (ii) transparency, we regress debt prices on (log) debt level and (log) transparency, jointly instrumented by the expenditure shock and the productivity shock. ${ }^{28}$ We find that one additional percent increase in debt, as a fraction of output, decreases debt prices by 0.0011 . One additional percent increase in transparency increases debt prices by 0.0006 . Both effects are large but they mitigate each other; a fiscal shock indeed affects jointly debt and transparency.

We next explore the dynamics of fiscal policy and default when default risk exerts a constraint on government choices. To do so, we use two environments: (i) the benchmark simulated economy in which the behavioral response of the economy adds to the previous external constraint; (ii) a counterfactual economy with a similar steady-state environment but a smaller behavioral response of entrepreneurs.

\subsection{Counterfactual experiments}

In order to shed light on the dynamic properties of our model and the importance of our novel behavioral response, we provide key descriptive statistics of the baseline economy and a similar economy in all aspects but one: technological choices are modeled to be less responsive to changes in taxes; the (semi-)elasticity of transparency to tax rate is set equal to -0.20 . Concretely, we shift the uniformly-distributed returns in the informal sector $H(\cdot)$. We then simulate 1,000 economies over 100 periods (years) in both cases, using the same primitives - apart from the ones disciplining the volatility of tax compliance - and the same shock structure.

variates (i.e., the shocks in the simulations) make them less distortionary, and the conditional effect captured in policy functions is a lower bound for the average sensitivity of default risk during fiscal consolidations.

${ }^{27}$ We collect the episodes of fiscal consolidation classified by Alesina et al. (2016) across our 30 countries and 30 years, and regress the change in 10-year bond spread on the size of these fiscal consolidations. We provide the detailed estimates in Appendix Table A3. Fiscal consolidations are associated with a marked decrease in default risk, but only in the group of low-volatility countries.

${ }^{28}$ Again, these quantities cannot be identified in the data, in the absence of well-identified sources of exogenous shocks. 
Default and debt ceiling We first report the average debt level, the average transparency and the occurrence of default in both scenarios (see Panel A of Table 8). The counterfactual economy is able to accumulate more debt on average $(19.3 \%$ of output, versus 16.3\%); this difference is non-negligible as it only arises from the sensitivity of technological choices to the tax rates - the shockless steady-state economies would coincide. The higher debt level induces higher tax rates and lower transparency in the counterfactual economy. ${ }^{29}$ Default is also slightly more likely.

We further illustrate the relationship between debt, transparency and default in Figure 3. The top panels (a) and (b) display the distribution of debt and transparency in the simulated benchmark economies; the red lines represent average expected default as a function of inherited debt and transparency. We contrast these distributions and default schedules with those of the simulated counterfactual economies - panels (c) and (d). The dynamics of debt and fiscal policy in the two environments crucially differ along a number of dimensions. First, the government faces a very steep debt price schedule for high levels of debt and low levels of transparency in the benchmark economy; the counterfactual economy does not appear to exhibit such strong dependence of default risk on past transparency. Second, the counterfactual economy exhibits a less dispersed distribution of debt but a more dispersed distribution of transparency. Debt can be, and is indeed, stabilized by fiscal policy in the counterfactual environment; this stabilization allows to sustain debt levels very close to a "debt ceiling". This does not hold in the benchmark economy. Third, the government in the benchmark economy more frequently chooses extreme fiscal policies leading to very high or very low levels of transparency. Both choices are associated with higher default. This finding would be consistent with a "double or nothing" bet, appearing only in the highly-distorted economy; we further investigate this behavior in the following section.

Extreme fiscal policies under default risk Extreme fiscal policies should appear under the constraint of limited commitment to reimburse debt. Without such constraint, the government would smooth consumption and limit wide fluctuations in tax rates.

We restrict the analysis to default risk episodes. A default risk episode is defined as all consecutive periods with non-zero default risk - this definition intends to capture periods where local variations in debt or transparency do affect debt prices.

\footnotetext{
${ }^{29}$ Note that this finding is not intended to replicate cross-country differences in the debt level or size of the informal sector. Indeed, we only vary the marginal response of transparency around the steady-state and force the two steady-state economies to be equal. In general, however, a country with higher tax enforcement would also exhibit markedly higher steady-state transparency levels.
} 
Panel B of Table 8 displays the frequency and end outcome of default risk episodes in the baseline and counterfactual economies. In the economy where fiscal policy is constrained by the response of entrepreneurs, these episodes are infrequent $(2.6 \%$ of all periods, versus $16 \%$ in the counterfactual scenario) but they often lead to a default ( $16 \%$ versus $3.5 \%$ in the counterfactual scenario). ${ }^{30}$

These default risk episodes are the source of differences observed in Figure 3 between the baseline economy and the counterfactual economy. In the former, default risk episodes are either associated with very low or very high levels of transparency. The government sometimes implements a very lenient fiscal policy at the expense of debt levels (right tail of Figure 3, panel b), or the government imposes a period of extreme austerity (left tail of Figure 3, panel b). Both choices often lead to a default, as illustrated by the humps in default risk observed at both ends of the transparency distribution (above .82 or below .68). In the counterfactual economy, the government instead implements reasonable fiscal consolidations during default risk episodes, with transparency ranging between .68 and .72. These fiscal consolidations are quite unlikely to lead to a default.

The (different) nature of default risk episodes across environments can be further identified looking at average tax rates. We define an austerity spell as an entire default risk episode, irrespectively of its length or outcome, during which the average tax rate was in the top quartile over all periods. ${ }^{31}$ These austerity spells correspond to observations stacked at the very left end of the transparency distribution (see Figure 3, panels b and d). As shown in Panel $\mathrm{C}$ of Table 8, austerity spells are more likely in the benchmark economy: $60 \%$ of default risk episodes are austerity spells. Surprisingly, these austerity spells are not more likely to lead to a default than non-austerity spells. This relates to the nature of non-austerity spells in the benchmark economy: these periods correspond to "double or nothing bets" where the government implements a very lenient fiscal policy, equally very likely to lead to a default.

The contrast with the counterfactual economy is striking: only $32 \%$ of default risk episodes are austerity spells and default is then unlikely (2.5\% of auterity spells end in an actual default). The large response of technological choices to fiscal policy strongly affects the set of desirable fiscal policies in turbulent times. Economies facing low distortions implement standard fiscal consolidations. High distortions push fiscal policy towards "corner solutions".

\footnotetext{
${ }^{30}$ Note that these default episodes are usually quite long; they last about 4 years in both caseswhen they are followed by an actual default.

${ }^{31}$ If fiscal policy was orthogonal to default risk, the frequency of austerity spells within default risk episodes would be (much) lower than .25, as we consider an average across several periods.
} 
In conclusion, imperfect tax enforcement - as only captured by the sensitivity of technological choices to the tax rates - does not produce different default rates across environments. This finding however masks markedly distinct behaviors of fiscal policy under default risk. Imperfect tax enforcement forces the government to implement extreme fiscal policies, sometimes very costly fiscal consolidations which are still unable to prevent default, sometimes very lenient policies. The latter case appears when fiscal consolidations become too inefficient and the only possible way out is to release tax pressure. These findings may rationalize two contrasting recoveries from default risk in peripheral European economies, both plagued by tax evasion: Greece and Portugal before 2014 (with extreme austerity) and Portugal after 2014 (with more expansionary fiscal policy during the recovery).

\section{Final remarks}

We study the empirical fluctuations in tax compliance, and show that there are important differences across countries in the volatility of tax compliance, and its response to economic conditions, most notably the tax rate. We then introduce imperfect tax enforcement in a simple model of sovereign debt with limited commitment. We show that the interaction of limited commitment and imperfect tax enforcement strongly constrains the dynamics of fiscal policy during default crises.

In economies plagued by tax evasion, fiscal policy influences the technological choice of entrepreneurs, which affects the future trade-off between repayment and default. Following a string of negative shocks, economies subject to these internal fiscal distortions may face very low returns to fiscal consolidations. We show that this mechanism leads to a restricted set of fiscal policies during default crises. Most often, the government implements costly austerity spells. These periods are selfsustained: high tax rates generate long-run distortions which affect default risk, and such high default risk forces the government to persevere with austerity policies. The economy can either exit after a negative shock and the government defaults, or the economy needs a series of positive shocks to reduce the impact of distortions on debt service. Sometimes, the cost of austerity becomes too high and the government then implements expansionary fiscal policies, again, often sanctioned by a default.

These results may inform the large policy debate on optimal fiscal policy during debt crises. As in Pappa et al. (2015), tax evasion in our model strongly influences the size of the fiscal multiplier, particularly in countries with limited commitment both toward foreign creditors, and toward their own tax payers. In such environment, the austerity plans advocated by multilateral lenders may fail in generating any positive returns on debt service. 


\section{References}

Aguiar, Mark and Gita Gopinath, "Defaultable debt, interest rates and the current account," Journal of international Economics, 2006, 69 (1), 64-83.

_ and Manuel Amador, "Fiscal policy in debt constrained economies," Journal of Economic Theory, 2016, 161, 37-75.

_, , , and Gita Gopinath, "Efficient fiscal policy and amplification," Technical Report, National Bureau of Economic Research 2005.

Aizenmann, Joshua and Yothin Jinjarak, "The collection efficiency and the value added tax: theory and international evidence," NBER Working Papers 11539, National Bureau of Economic Research August 2005.

Alesina, Alberto F. and Silvia Ardagna, "Large Changes in Fiscal Policy: Taxes Versus Spending," Working Paper 15438, National Bureau of Economic Research October 2009.

Alesina, Alberto, Filipe R. Campante, and Guido Tabellini, "Why is Fiscal Policy Often Procyclical?," Journal of the European Economic Association, 09 2008, 6 (5), 1006-1036.

_, Gualtiero Azzalini, Carlo Favero, Francesco Giavazzi, and Armando Miano, "Is it the" How" or the" When" that Matters in Fiscal Adjustments?," Technical Report, National Bureau of Economic Research 2016.

_ , Omar Barbiero, Carlo Favero, Francesco Giavazzi, and Matteo Paradisi, "Austerity in 2009-2013," NBER Working Papers 20827, National Bureau of Economic Research January 2015.

Alesina, Roberto Perotti Alberto, "Fiscal Discipline and the Budget Process," The American Economic Review, 1996, 86 (2), 401-407.

Arellano, Cristina, "Default Risk and Income Fluctuations in Emerging Economies," American Economic Review, 2008, 98 (3), 690-712.

_ and Yan Bai, "Fiscal austerity during debt crises," Economic Theory, 2016, pp. $1-17$.

Auerbach, Alan J. and Yuriy Gorodnichenko, "Measuring the Output Responses to Fiscal Policy," American Economic Journal: Economic Policy, May 2012, 4 (2), 1-27.

Bi, Huixin, "Sovereign default risk premia, fiscal limits, and fiscal policy," European Economic Review, 2012, 56 (3), 389-410.

Bocola, Luigi, "The pass-through of sovereign risk," Journal of Political Economy, 2016, 124 (4), 879-926. 
Cai, Hongbin and Qiao Liu, "Competition and Corporate Tax Avoidance: Evidence from Chinese Industrial Firms," Economic Journal, 04 2009, 119 (537), $764-795$.

Calderón, César and Klaus Schmidt-Hebbel, "Business Cycles and Fiscal Policies: the Role of Institutions and financial Markets," Working Papers Central Bank of Chile 481, Central Bank of Chile August 2008.

Calvo, Guillermo A, "Staggered prices in a utility-maximizing framework," Journal of Monetary Economics, 1983, 12 (3), 383-398.

Cuadra, Gabriel, Juan M Sanchez, and Horacio Sapriza, "Fiscal policy and default risk in emerging markets," Review of Economic Dynamics, 2010, 13 (2), $452-469$.

D'Erasmo, Pablo and Enrique G. Mendoza, "Distributional Incentives in an Equilibrium Model of Domestic Sovereign Default," NBER Working Papers 19477, National Bureau of Economic Research, Inc September 2013.

Dovis, Alessandro, Mikhail Golosov, and Ali Sourideh, "Political Economy of Sovereign Debt: Cycles of Debt Crisis and Inequality Overhang," Working Paper May 2015.

Eaton, Jonathan and Mark Gersovitz, "Debt with Potential Repudiation: Theoretical and Empirical Analysis," The Review of Economic Studies, 1981, 48 (2), 289-309.

Enste, Dominik H. and Friedrich Schneider, "Shadow Economies: Size, Causes, and Consequences," Journal of Economic Literature, March 2000, 38 (1), $77-114$.

Favero, Carlo, Francesco Giavazzi, and Jacopo Perego, "Country Heterogeneity and the International Evidence on the Effects of Fiscal Policy," IMF Economic Review, Palgrave Macmillan, November 2011, 59 (4), 652-682.

Fisman, Raymond and Shang-Jin Wei, "Tax Rates and Tax Evasion: Evidence from Missing Imports in China," Journal of Political Economy, April 2004, 112 (2), 471-500.

Frankel, Jeffrey A., Carlos A. Vegh, and Guillermo Vuletin, "On graduation from fiscal procyclicality," Journal of Development Economics, 2013, 100 (1), 3247.

Ghosh, Atish R., Jun I. Kim, Enrique G. Mendoza, Jonathan D. Ostry, and Mahvash S. Qureshi, "Fiscal Fatigue, Fiscal Space and Debt Sustainability in Advanced Economies," Economic Journal, 02 2013, 0, F4-F30.

Hatchondo, Juan Carlos, Leonardo Martinez, and Horacio Sapriza, "Quantitative properties of sovereign default models: solution methods matter," Review of Economic Dynamics, 2010, 13 (4), 919-933. 
Ilzetski, Ethan and Carlos Vegh, "Procyclical Fiscal Policy in Developing Countries: Truth or Fiction?," NBER Working Papers 14191 August 2008.

Ilzetzki, Ethan, Enrique G. Mendoza, and Carlos A. Végh, "How big (small?) are fiscal multipliers?," Journal of Monetary Economics, 2013, 60 (2), 239-254.

Kaminsky, Graciela L., Carmen M. Reinhart, and Carlos A. Vegh, "When it Rains, it Pours: Procyclical Capital Flows and Macroeconomic Policies," NBER Working Papers 10780, National Bureau of Economic Research, Inc September 2004 .

Kleven, Henrik Jacobsen, Martin B. Knudsen, Claus Thustrup Kreiner, Soren Pedersen, and Emmanuel Saez, "Unwilling or Unable to Cheat? Evidence From a Tax Audit Experiment in Denmark," Econometrica, 2011, 79 (3).

Mendoza, Enrique G. and Vivian Z. Yue, "A General Equilibrium Model of Sovereign Default and Business Cycles," The Quarterly Journal of Economics, 2012, $127(2), 889-946$.

Pappa, Evi, Rana Sajedi, and Eugenia Vella, "Fiscal consolidation with tax evasion and corruption," Journal of International Economics, 2015, 96 (S1), 5675 .

Pappadà, Francesco and Yanos Zylberberg, "Austerity and tax compliance," European Economic Review, 2017, 100 (C), 506-524.

Pomeranz, Dina, "No taxation without information: Deterrence and selfenforcement in the value added tax," The American economic review, 2015, 105 (8), 2539-2569.

Qian, Rong, Carmen M. Reinhart, and Kenneth S. Rogoff, "On Graduation from Default, Inflation and Banking Crisis: Elusive or Illusion?," NBER Working Papers 16168, National Bureau of Economic Research, Inc July 2010.

Rauch, James E., "Modelling the informal sector formally," Journal of Development Economics, January 1991, 35 (1), 33-47.

Romer, Christina D. and David H. Romer, "The Macroeconomic Effects of Tax Changes: Estimates Based on a New Measure of Fiscal Shocks," American Economic Review, June 2010, 100 (3), 763-801.

Schneider, Friedrich and Dominik H Enste, The shadow economy: An international survey, Cambridge University Press, 2013.

Straub, Stéphane, "Informal sector: The credit market channel," Journal of Development Economics, December 2005, 78 (2), 299-321.

Tauchen, George, "Finite state markov-chain approximations to univariate and vector autoregressions," Economics letters, 1986, 20 (2), 177-181. 
Tomz, Michael and Mark LJ Wright, "Do countries default in "bad times"?," Journal of the European Economic association, 2007, 5 (2-3), 352-360.

Tornell, Philip R. Lane Aaron, "The Voracity Effect," The American Economic Review, 1999, 89 (1), 22-46.

Vegh, Carlos A. and Guillermo Vuletin, "How is Tax Policy Conducted over the Business Cycle?," Forthcoming, American Economic Journal: Economic Policy, 2015 .

von Hagen, Juergen and Ian J. Harden, "Budget processes and commitment to fiscal discipline," European Economic Review, 1995, 39 (3-4), 771-779.

Williamson, Stephen D, "Costly Monitoring, Loan Contracts, and Equilibrium Credit Rationing," The Quarterly Journal of Economics, February 1987, 102 (1), $135-45$. 


\section{Figures and tables}

Figure 1. Volatility in VAT compliance and the size of the informal sector (red: above-median volatility, blue: below-median volatility).

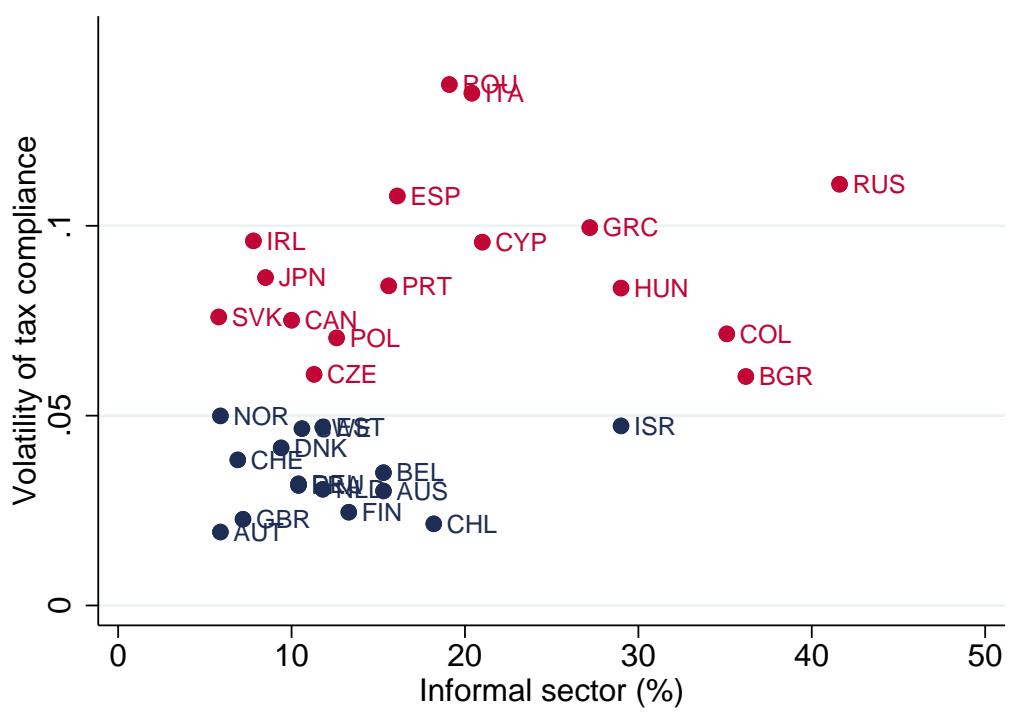

Notes: This Figure displays the within-country standard deviation of VAT compliance along the y-axis (1995-2013), and the size of the informal sector (2005-2012) as computed in Schneider and Enste (2013).

Figure 2. Policy functions and debt pricing schedule as a function of inherited transparency and debt.
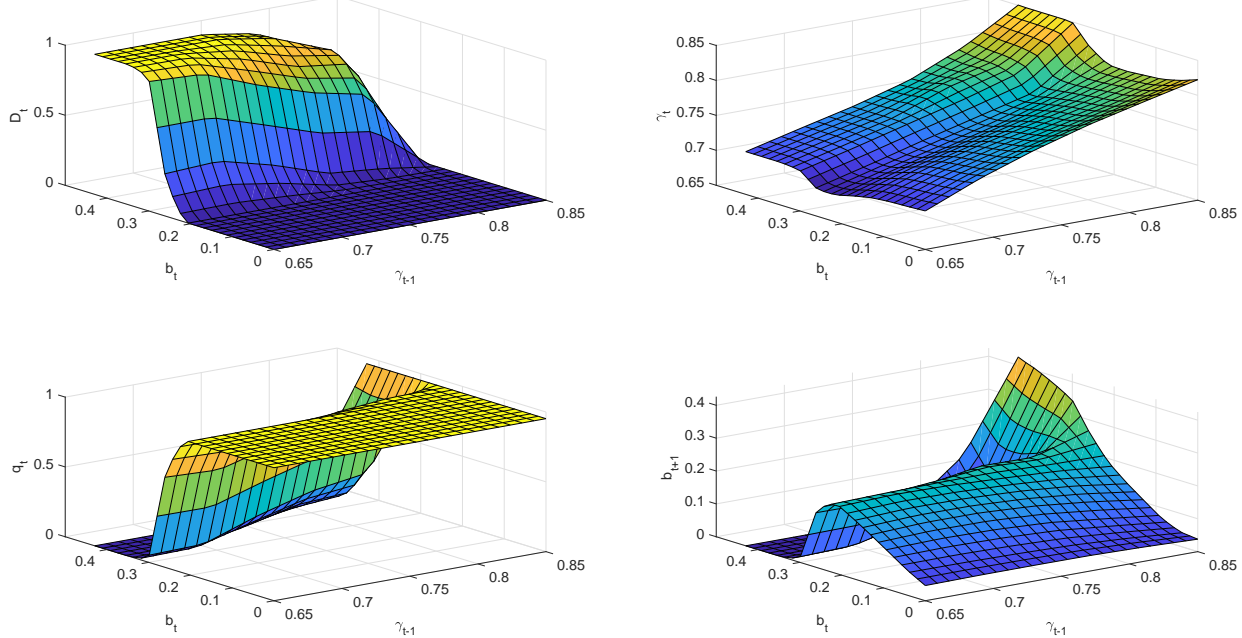

Notes: This Figure displays the policy choice as a multivariate function of $b_{t}$ and $\gamma_{t-1}$, and averaged over all other state variables. 
Figure 3. Distribution of debt and transparency in the baseline economy and in the counterfactual economy.

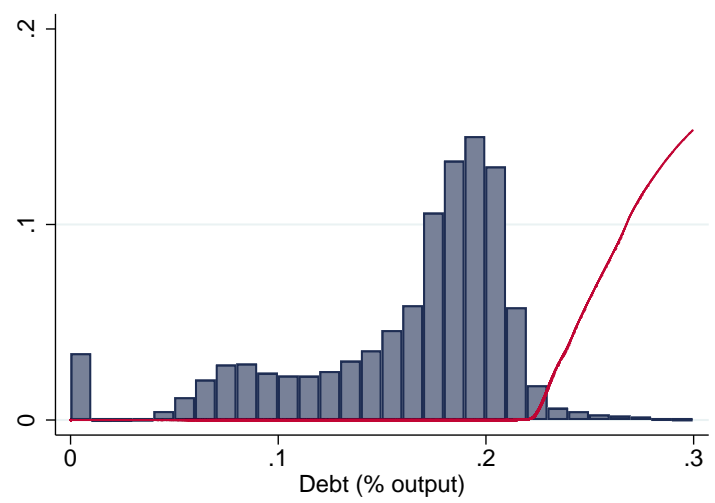

(a) Debt (\% of output, benchmark).

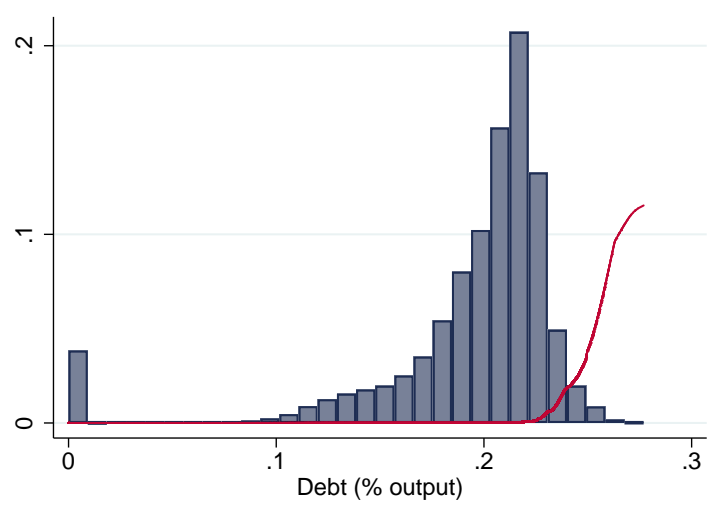

(c) Debt (\% of output, counterfactual)

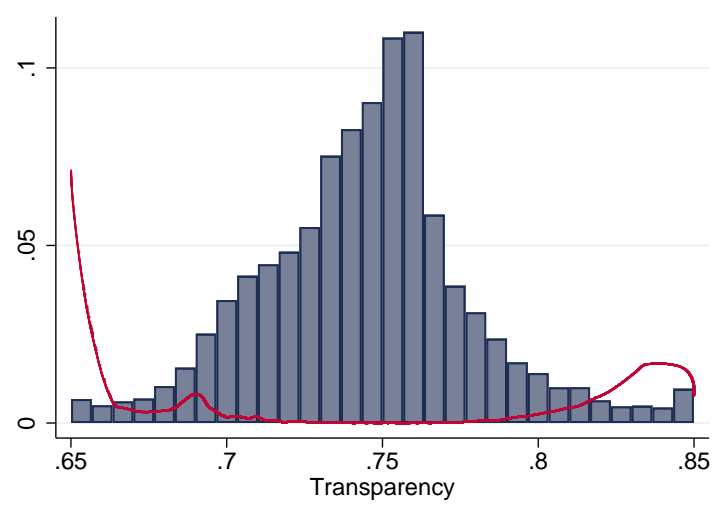

(b) Transparency (benchmark).

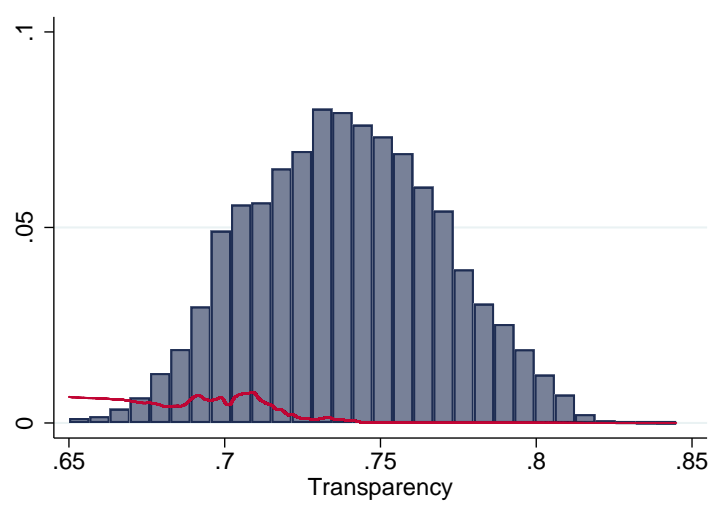

(d) Transparency (counterfactual).

Notes: The Baseline (top panels) and Counterfactual results (bottom panels) are derived from simulating 1,000 economies characterized, and hit by productivity and expenditure shocks over 100 periods (years). The red lines are local regressions using expected default as the dependent variable. 
Table 1. Descriptive statistics.

\begin{tabular}{|c|c|c|c|c|c|}
\hline & \multicolumn{3}{|c|}{ Sample } & \multirow{2}{*}{$\begin{array}{c}\text { Coeff. } \\
\text { variation }\end{array}$} & \multirow[b]{2}{*}{ Cyclicality } \\
\hline & All & High-vol & Low-vol & & \\
\hline Tax revenue (\% GDP) & 21.44 & 20.15 & 22.62 & .103 & 0.078 \\
\hline Corporate tax (\% revenue) & 15.16 & 16.51 & 14.21 & .176 & 0.122 \\
\hline Income tax ( $\%$ revenue $)$ & 28.85 & 28.03 & 29.43 & .133 & -0.027 \\
\hline Value-added tax (\% revenue) & 31.72 & 31.14 & 32.13 & .096 & 0.028 \\
\hline Corporate tax rate (\%) & 27.97 & 27.40 & 28.41 & .158 & -0.041 \\
\hline Income tax rate $(\%)$ & 42.16 & 37.20 & 46.09 & .170 & -0.056 \\
\hline Value-added tax rate (\%) & 14.7 & 13.57 & 14.87 & .087 & -0.205 \\
\hline VAT Compliance ratio & .874 & .843 & .902 & .095 & 0.327 \\
\hline
\end{tabular}

Notes: The coefficient of variation is the average coefficient of variation computed for each country (standard deviation/mean). The Cyclicality index is computed by taking the annual change in the dependent variable, and estimate its correlation with the annual change in HP filtered GDP per capita. See Section 2 for the definition of High- and low-volatility countries.

Table 2. Elasticities of tax compliance to cyclical fluctuations.

\begin{tabular}{|c|c|c|c|c|}
\hline Tax compliance & $(1)$ & $(2)$ & $(3)$ & $(4)$ \\
\hline Panel A: Average effect & & & & \\
\hline GDP growth & $\begin{array}{c}.392 \\
(.108)\end{array}$ & $\begin{array}{c}.395 \\
(.124)\end{array}$ & $\begin{array}{c}.408 \\
(.124)\end{array}$ & $\begin{array}{c}.401 \\
(.139)\end{array}$ \\
\hline Observations & 602 & 524 & 524 & 419 \\
\hline Tax compliance & $(1)$ & $(2)$ & $(3)$ & $(4)$ \\
\hline Panel B: Heterogeneous effect & & & & \\
\hline GDP growth & $\begin{array}{c}.018 \\
(.146)\end{array}$ & $\begin{array}{c}.060 \\
(.157)\end{array}$ & $\begin{array}{c}.083 \\
(.159)\end{array}$ & $\begin{array}{c}.022 \\
(.167)\end{array}$ \\
\hline GDP growth $\times$ High-volatility & $\begin{array}{c}.582 \\
(.157)\end{array}$ & $\begin{array}{c}.565 \\
(.167)\end{array}$ & $\begin{array}{c}.545 \\
(.168)\end{array}$ & $\begin{array}{c}.637 \\
(.171)\end{array}$ \\
\hline Observations & 602 & 524 & 524 & 419 \\
\hline \multicolumn{5}{|l|}{ Controls } \\
\hline Sectoral composition & No & Yes & Yes & Yes \\
\hline Trade & No & No & Yes & Yes \\
\hline Government expenditures & No & No & No & Yes \\
\hline
\end{tabular}


Table 3. Elasticities of tax compliance to VAT standard rates.

\begin{tabular}{|c|c|c|c|c|}
\hline Tax compliance & (1) & $(2)$ & $(3)$ & $(4)$ \\
\hline \multicolumn{5}{|l|}{ Panel A: Average effect } \\
\hline Tax rate & $\begin{array}{l}-.368 \\
(.055)\end{array}$ & $\begin{array}{l}-.385 \\
(.057)\end{array}$ & $\begin{array}{l}-.379 \\
(.057)\end{array}$ & $\begin{array}{l}-.371 \\
(.081)\end{array}$ \\
\hline Observations & 539 & 477 & 477 & 385 \\
\hline Tax compliance & $(1)$ & $(2)$ & $(3)$ & $(4)$ \\
\hline \multicolumn{5}{|c|}{ Panel B: Heterogeneous effect } \\
\hline Tax rate & $\begin{array}{l}-.110 \\
(.116)\end{array}$ & $\begin{array}{l}-.115 \\
(.121)\end{array}$ & $\begin{array}{l}-.104 \\
(.121)\end{array}$ & $\begin{array}{l}-.053 \\
(.136)\end{array}$ \\
\hline Tax rate $\times$ High-volatility & $\begin{array}{l}-.327 \\
(.130)\end{array}$ & $\begin{array}{l}-.341 \\
(.137)\end{array}$ & $\begin{array}{l}-.347 \\
(.137)\end{array}$ & $\begin{array}{l}-.477 \\
(.165)\end{array}$ \\
\hline Observations & 539 & 477 & 477 & 385 \\
\hline Controls & & & & \\
\hline Sectoral composition & No & Yes & Yes & Yes \\
\hline Trade & No & No & Yes & Yes \\
\hline Government expenditures & No & No & No & Yes \\
\hline
\end{tabular}

Table 4. Elasticities of tax compliance to VAT standard rates - heterogeneity along the cycle.

\begin{tabular}{lccc}
\hline Tax compliance & $(1)$ & $(2)$ & $(3)$ \\
\hline Tax rate & -.283 & -.293 & $(.298$ \\
Tax rate $\times$ Recession 1 & $(.114)$ & $(.104)$ & \\
Tax rate $\times$ Recession 2 & -.172 & & \\
& $(.149)$ & -.185 & -.149 \\
Tax rate $\times$ Recession 3 & & $(.151)$ & $(.150)$ \\
& & & 419 \\
Observations & & & Yes \\
Sectoral composition & 419 & 419 & Yes \\
Trade & Yes & Yes & Yes \\
Government expenditures & Yes & Yes & Yes \\
\hline
\end{tabular}

Notes: Robust standard errors are reported between parentheses. All specifications include year- and country-fixed effects. The dependent variable is the yearly percentage change in VAT compliance. Tax rate is the yearly percentage change in VAT standard rate. Recession 1 is equal to 1 when the HP-filtered GDP is negative; Recession 2 is equal to 1 when the HP-filtered GDP is below the 25th percentile; Recession 3 dummy is equal to 1 when the HP-filtered GDP is below the 50th percentile. 
Table 5. Persistence of VAT compliance.

\begin{tabular}{lcc}
\hline Tax compliance & OLS & IV \\
\hline Tax compliance in $t-1$ & $(1)$ & $(2)$ \\
& .515 & .748 \\
Observations & $(.042)$ & $(.222)$ \\
F-stat (first stage) & 448 & 448 \\
\hline
\end{tabular}

Notes: Robust standard errors are reported between parentheses. All specifications include year- and country-fixed effects, controls for GDP growth and controls for yearly changes in industrial composition. The instrument in the IV specification is the yearly change in tax rates.

Table 6. Calibrated parameters.

\begin{tabular}{|c|c|c|c|}
\hline Parameter & & Value & Rationale \\
\hline \multicolumn{4}{|l|}{ Preferences } \\
\hline Discount factor & $\beta$ & 0.90 & Aguiar and Gopinath (2006) \\
\hline Interest rate & $r$ & 0.05 & \\
\hline Risk-aversion (CRRA) & $s$ & 2 & Aguiar and Gopinath (2006) \\
\hline \multicolumn{4}{|l|}{ Technology } \\
\hline Distribution (informal) & $a_{1}$ & -0.10 & Steady-state tax compliance \\
\hline Distribution (informal) & $a_{2}$ & 1.11 & Steady-state tax compliance \\
\hline Complementarities & $\phi$ & 0.86 & Elasticity of tax compliance \\
\hline Probability to set technology & $\theta$ & 0.50 & Persistence of tax compliance \\
\hline \multicolumn{4}{|l|}{ Default } \\
\hline Probability of reintegration & $\nu$ & 0.05 & Arellano (2008) \\
\hline Output cost & $\delta$ & 0.05 & Arellano (2008) \\
\hline \multicolumn{4}{|l|}{ Shocks } \\
\hline TFP $z$, autocorrelation & $\rho_{z}$ & 0.80 & GDP autocorrelation \\
\hline $\mathrm{TFP} z$, standard deviation & $\sigma_{z}$ & 0.016 & GDP volatility \\
\hline Expenditures $g$, autocorrelation & $\rho_{g}$ & 0.80 & Spending autocorrelation \\
\hline Expenditures $g$, standard deviation & $\sigma_{g}$ & 0.10 & Spending volatility \\
\hline
\end{tabular}


Table 7. Sensitivity of transparency to cyclical fluctuations and tax rates-simulated and empirical moments.

\begin{tabular}{|c|c|c|}
\hline & Model & Data \\
\hline Panel A: Targeted moment & & \\
\hline (Semi-)elasticity of transparency to tax rate & $\begin{array}{l}-.393 \\
(.001)\end{array}$ & $\begin{array}{c}-.385 \\
(.057)\end{array}$ \\
\hline Panel B: Untargeted moments & & \\
\hline (Semi-)elasticity of transparency to the cycle & $\begin{array}{c}.528 \\
(.002)\end{array}$ & $\begin{array}{c}.401 \\
(.139)\end{array}$ \\
\hline Sensitivity of debt prices to fiscal consolidation & $\begin{array}{l}-.120 \\
(.003)\end{array}$ & $\begin{array}{l}-.182 \\
(.068)\end{array}$ \\
\hline
\end{tabular}

Notes: The Model results are derived from simulating 1,000 economies characterized by the same primitives as our baseline calibrated economy, and hit by productivity and expenditure shocks over 100 periods (years).

Table 8. Simulated moments in the baseline economy and in the counterfactual economy.

\begin{tabular}{lcc}
\hline & $\begin{array}{c}\text { Baseline } \\
\varepsilon_{\gamma}=-0.39\end{array}$ & $\begin{array}{c}\text { Counterfactual } \\
\varepsilon_{\gamma}=-0.20\end{array}$ \\
\hline Panel A: Debt level and default & .1628 & .1933 \\
Debt level (\% output) & {$[.0550]$} & {$[.0487]$} \\
Transparency & .7448 & .7388 \\
& {$[.0338]$} & {$[.0305]$} \\
Default occurrence & .0016 & .0019 \\
$\quad$ Panel B: Episodes of default risk & .0260 & .1671 \\
Occurrence & .1559 & .0357 \\
Exit is default & & \\
\hline$\quad$ Panel C: Austerity spells & .6097 & .3229 \\
Occurrence if default risk & .1488 & .0255 \\
Exit is default &
\end{tabular}

Notes: The Baseline and Counterfactual results are derived from simulating 1,000 economies characterized, and hit by productivity and expenditure shocks over 100 periods (years). 


\section{Online Appendix}

\section{A Additional tables and figures}

Table A1. Robustness analysis - heterogeneity along the volatility of VAT compliance versus "developed" economies.

\begin{tabular}{|c|c|c|c|c|}
\hline Tax compliance & (1) & $(2)$ & $(3)$ & $(4)$ \\
\hline \multicolumn{5}{|l|}{ Panel A: Cycle } \\
\hline \multirow[t]{2}{*}{ GDP growth } & -.006 & .069 & .092 & .063 \\
\hline & $(.160)$ & $(.174)$ & $(.175)$ & $(.188)$ \\
\hline \multirow[t]{2}{*}{ GDP growth $\times$ High-volatility } & .657 & .611 & .589 & .753 \\
\hline & $(.160)$ & $(.171)$ & $(.172)$ & $(.181)$ \\
\hline \multirow[t]{2}{*}{ GDP growth $\times$ Industrial } & .008 & -.017 & -.012 & -.114 \\
\hline & $(.168)$ & $(.183)$ & $(.182)$ & $(.191)$ \\
\hline Observations & 558 & 485 & 485 & 392 \\
\hline Tax compliance & (1) & $(2)$ & $(3)$ & $(4)$ \\
\hline \multicolumn{5}{|l|}{ Panel B: Tax rate } \\
\hline \multirow[t]{2}{*}{ Tax rate } & -.089 & -.154 & -.136 & -.374 \\
\hline & $(.151)$ & $(.168)$ & $(.168)$ & $(.229)$ \\
\hline \multirow[t]{2}{*}{ Tax rate $\times$ High-volatility } & -.334 & -.311 & -.319 & -.225 \\
\hline & $(.134)$ & $(.143)$ & $(.143)$ & $(.209)$ \\
\hline \multirow[t]{2}{*}{ Tax rate $\times$ Industrial } & -.044 & .034 & .023 & .318 \\
\hline & $(.112)$ & $(.122)$ & $(.123)$ & $(.199)$ \\
\hline Observations & 558 & 485 & 485 & 392 \\
\hline \multicolumn{5}{|l|}{ Controls } \\
\hline Sectoral composition & No & Yes & Yes & Yes \\
\hline Trade & No & No & Yes & Yes \\
\hline Government expenditures & No & No & No & Yes \\
\hline
\end{tabular}


Table A2. Robustness analysis - elasticities of VAT rates to VAT effective rates.

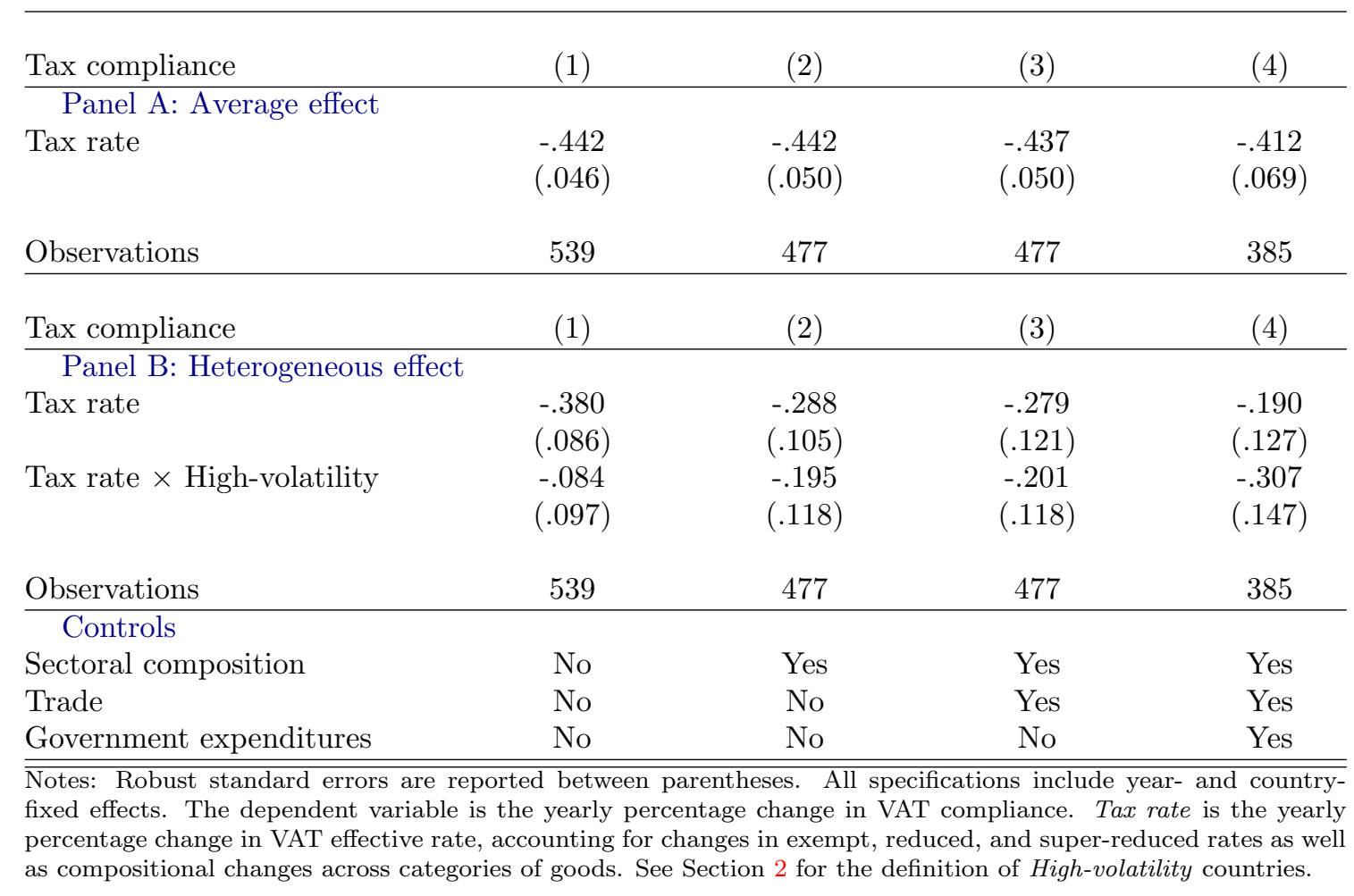

Table A3. Empirical moments - correlation between fiscal consolidations and default risk.

\begin{tabular}{lcc}
$\Delta$ Spread $(10$ yrs $)$ & $(1)$ & $(2)$ \\
\hline$\Delta$ Primary Balance & -.120 & -.118 \\
$\Delta$ Primary Balance $\times$ High-volatility & $(.031)$ & $(.032)$ \\
& .084 & $(.036)$ \\
Observations & $(.034)$ & 326 \\
Basic controls & 433 & Yes \\
Extended controls & Yes & Yes \\
\hline
\end{tabular}

Notes: Robust standard errors are reported between parentheses. All specifications include year- and country-fixed effects. Units of observation are episodes of large fiscal consolidations (changes in fiscal surplus above $1 \%$ of output). The dependent variable is the change in 1-year bond spread and the explaining variable is the size of the fiscal consolidation. See Section 2 for the definition of the High-volatility dummy. 
Table A4. Empirical moments - correlation between fiscal policy and output.

\begin{tabular}{|c|c|c|c|c|}
\hline Tax rate & $(1)$ & $(2)$ & $(3)$ & $(4)$ \\
\hline \multicolumn{5}{|l|}{ Panel A: Average effect } \\
\hline Cycle & $\begin{array}{l}-.381 \\
(.101)\end{array}$ & $\begin{array}{l}-.333 \\
(.111)\end{array}$ & $\begin{array}{l}-.343 \\
(.111)\end{array}$ & $\begin{array}{l}-.347 \\
(.104)\end{array}$ \\
\hline Observations & 539 & 477 & 477 & 385 \\
\hline Sectoral composition & No & Yes & Yes & Yes \\
\hline Trade & No & No & Yes & Yes \\
\hline Government expenditures & No & No & No & Yes \\
\hline Tax rate & $(1)$ & $(2)$ & $(3)$ & $(4)$ \\
\hline \multicolumn{5}{|c|}{ Panel B: Heterogeneous effect } \\
\hline Cycle & $\begin{array}{c}-.183 \\
(.131)\end{array}$ & $\begin{array}{l}-.218 \\
(.136)\end{array}$ & $\begin{array}{l}-.226 \\
(.137)\end{array}$ & $\begin{array}{l}-.205 \\
(.125)\end{array}$ \\
\hline Cycle $\times$ High-debt & $\begin{array}{l}-.265 \\
(.143)\end{array}$ & $\begin{array}{l}-.216 \\
(.147)\end{array}$ & $\begin{array}{l}-.221 \\
(.147)\end{array}$ & $\begin{array}{l}-.258 \\
(.131)\end{array}$ \\
\hline Observations & 523 & 466 & 466 & 385 \\
\hline Controls & & & & \\
\hline Sectoral composition & No & Yes & Yes & Yes \\
\hline Trade & No & No & Yes & Yes \\
\hline Government expenditures & No & No & No & Yes \\
\hline
\end{tabular}




\section{B Complements on the production side}

Equilibrium in the formal sector The equation characterizing the equilibrium number of formal entrepreneurs is:

$$
\frac{\gamma_{t}-\theta \gamma_{t-1}}{1-\theta}=H\left[(1-\theta \beta) r_{t}+\theta \beta E_{t} H^{-1}\left(\frac{\gamma_{t+1}-\theta \gamma_{t}}{1-\theta}\right)\right],
$$

Such equation admits a unique "stable" equilibrium if

$$
h\left[R_{t}\right]\left[-E_{t} \frac{\theta^{2} \beta}{h\left(H^{-1}\left(\frac{\gamma_{t+1}-\theta \gamma_{t}}{1-\theta}\right)\right)}+(1-\theta)(1-\theta \beta)\left(1-\tau_{t}\right) a_{t} \gamma_{t}^{\frac{1}{\phi}-2}\left(\frac{1}{\phi}-1\right)\right]<1 .
$$

We ignore the unstable equilibrium $H(0)=0$, and we focus on the stable equilibrium with a positive number of entrepreneurs willing to work in the formal sector.

Formal sector and returns to the formal activity The equation characterizing the equilibrium number of entrepreneurs in the formal sector implicitly relates the size of the formal sector $\gamma_{t}$ to the aggregate relative returns to the formal sector, and to $z_{t}$ or $\tau_{t}$ in particular:

$$
\frac{\partial \gamma_{t}}{\partial z_{t}}=\frac{(1-\theta)(1-\theta \beta)\left(1-\tau_{t}\right) \gamma_{t}^{\frac{1}{\phi}-1} h\left[R_{t}\right]}{1+E_{t} \frac{\theta^{2} \beta h\left[R_{t}\right]}{h\left(R_{t+1}\right)}-(1-\theta)(1-\theta \beta)\left(1-\tau_{t}\right) z_{t} \gamma_{t}^{\frac{1}{\phi}-2}\left(\frac{1}{\phi}-1\right) h\left[R_{t}\right]},
$$

and

$$
\frac{\partial \gamma_{t}}{\partial \tau_{t}}=-\frac{z_{t}}{1-\tau_{t}} \frac{\partial \gamma_{t}}{\partial z_{t}}
$$

Tax receipts and output in equilibrium We write the tax receipts and the output net of taxes:

$$
\left\{\begin{array}{l}
t_{t}=\tau_{t} z_{t} \gamma_{t}^{\frac{1}{\phi}} \\
w_{t}=\left(1-\tau_{t}\right) z_{t} \gamma_{t}^{\frac{1}{\phi}}+\theta \int_{R_{t-1}}^{\infty} R h(R) d R+(1-\theta) \int_{R_{t}}^{\infty} R h(R) d R
\end{array}\right.
$$


Differentiating these expressions, we find that:

$$
\left\{\begin{array}{l}
\frac{\partial t_{t}}{\partial \tau_{t}}=z_{t} \gamma_{t}^{\frac{1}{\phi}}+\frac{z_{t} \tau_{t}}{\phi} \gamma_{t}^{\frac{1}{\phi}-1} \frac{\partial \gamma_{t}}{\partial \tau_{t}} \\
\frac{\partial w_{t}}{\partial \tau_{t}}=-z_{t} \gamma_{t}^{\frac{1}{\phi}}+z_{t}\left(1-\tau_{t}\right) \frac{1}{\phi} \gamma_{t}^{\frac{1}{\phi}-1} \frac{\partial \gamma_{t}}{\partial \tau_{t}}-(1-\theta) R_{t} h\left(R_{t}\right) \frac{\partial R_{t}}{\partial \tau_{t}}
\end{array}\right.
$$

Using the fact that $(1-\theta) h\left(R_{t}\right) \frac{\partial R_{t}}{\partial \tau_{t}}=\frac{\partial \gamma_{t}}{\partial \tau_{t}}$, we get:

$$
\left\{\begin{array}{l}
\frac{\partial t_{t}}{\partial \tau_{t}}=z_{t} \gamma_{t}^{\frac{1}{\phi}}+\frac{z_{t} \tau_{t}}{\phi} \gamma_{t}^{\frac{1}{\phi}-1} \frac{\partial \gamma_{t}}{\partial \tau_{t}} \\
\frac{\partial w_{t}}{\partial \tau_{t}}=-z_{t} \gamma_{t}^{\frac{1}{\phi}}+\left[\left(1-\tau_{t}\right) \frac{z_{t}}{\phi} \gamma_{t}^{\frac{1}{\phi}-1}-R_{t}\right] \frac{\partial \gamma_{t}}{\partial \tau_{t}}
\end{array}\right.
$$

These two expressions highlight the existing distortions exerted by taxes. Indeed, total output $w_{t}+t_{t}$ strongly depends on the transparency response $\frac{\partial \gamma_{t}}{\partial \tau_{t}}<0$ as follows:

$$
\frac{\partial\left(w_{t}+t_{t}\right)}{\partial \tau}=\left(\frac{z_{t}}{\phi} \gamma_{t}^{\frac{1}{\phi}-1}-R_{t}\right) \frac{\partial \gamma_{t}}{\partial \tau_{t}}<0
$$

Distortions also depend on the factor $\frac{z_{t}}{\phi} \gamma_{t}^{\frac{1}{\phi}-1}-R_{t}>0$. In the case $\theta=0$, this term simplifies and we get:

$$
\frac{\partial\left(w_{t}+t_{t}\right)}{\partial \tau}=\tau_{t} \frac{z_{t}}{\phi} \gamma_{t}^{\frac{1}{\phi}-1} \frac{\partial \gamma_{t}}{\partial \tau_{t}}<0
$$

A low $\phi$ would be associated with high complementarity in the formal sector, and taxes would then be particularly distortionary. 